\title{
Endophenotypes in Psychopathology Research: Where Do We Stand?
}

\author{
Gregory A. Miller ${ }^{1,2,3}$ and Brigitte Rockstroh ${ }^{4}$ \\ ${ }^{1}$ Department of Psychology, University of Delaware, Newark, \\ Delaware 19716; email: gamiller@udel.edu \\ ${ }^{2}$ Zukunftskolleg, University of Konstanz, 78457 Konstanz, Germany \\ ${ }^{3}$ Department of Psychology and Beckman Institute, University of \\ Illinois at Urbana-Champaign, Illinois 61820 \\ ${ }^{4}$ Department of Psychology, University of Konstanz, 78457 Konstanz, \\ Germany; email: brigitte.rockstroh@uni-konstanz.de
}

\section{Keywords}

RDoC, diagnosis, latent phenotype, intermediate phenotype, genetic risk

\begin{abstract}
Endophenotypes for psychopathology have been conceived as latent, unobserved, but measureable manifestations of phenomena that causally connect genetic liability to clinical disorder. Several decades of research have led to refinement of the construct and identification of some candidate endophenotypes, but rather limited progress on finding the genes involved or the mechanisms by which endophenotypes are driven by genetic and environmental factors and in turn drive psychopathology. Currently promising avenues for research involve development of transdiagnostic concepts not limited to traditional diagnostic categories, measures of endophenotypic and manifest psychopathology that have higher validity than those categories, and methods for modeling complex relationships among diverse contributors to etiology. With more grounding in animal neuroscience and other aspects of basic biological and psychological science, exemplified in the Research Domain Criteria initiative, there is every reason to anticipate that the endophenotype concept will grow more central in the psychopathology literature.
\end{abstract}




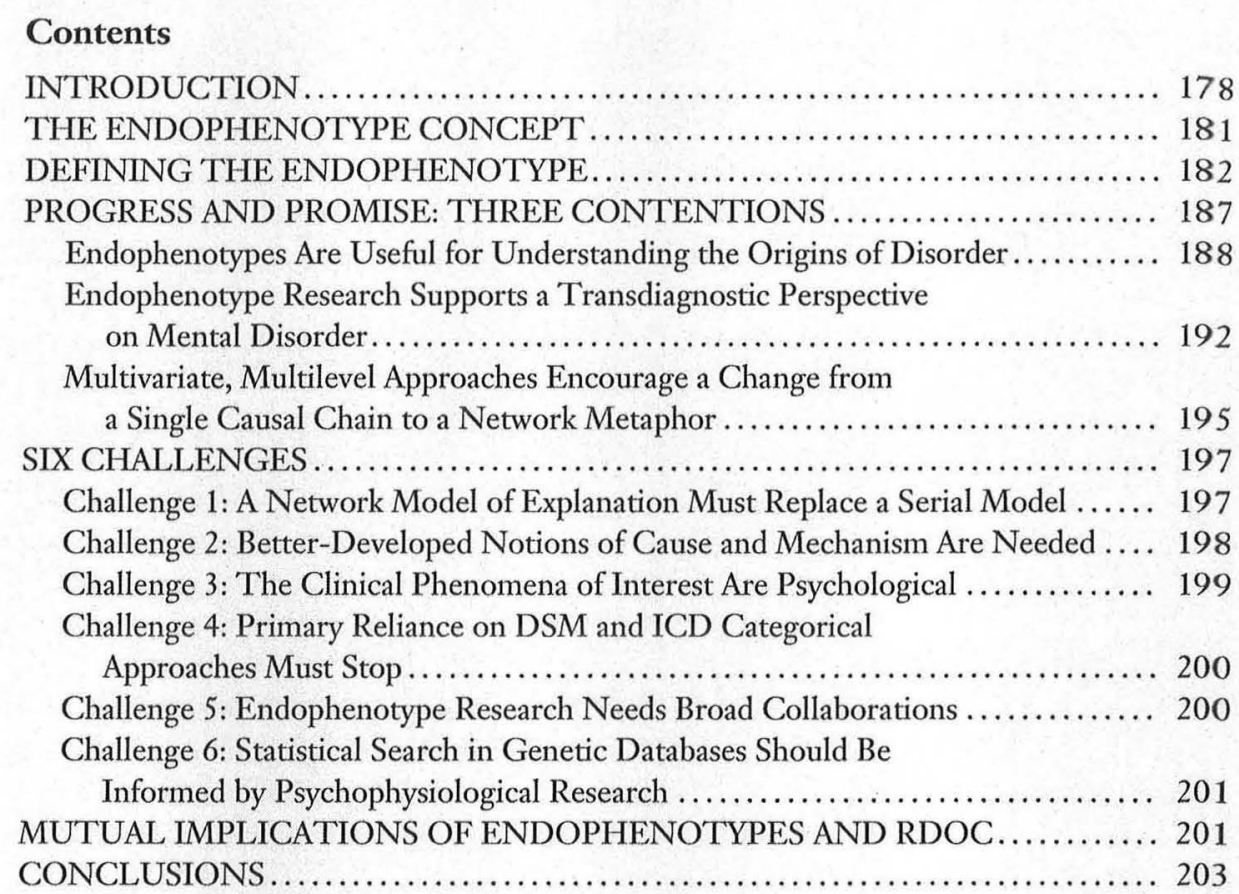

\section{INTRODUCTION}

At the close of her Annual Review of Clinical Psychology article, Dick (2011, p. 403) commented that in the psychopathology literature, "Much of the large-scale gene identification work to date has been dominated by studies of binary diagnostic outcomes. Although the use of binary diagnoses brings the advantage of standardized, reliable assessments across studies and sites, there is reason to believe that these phenotypes are not ideal for gene finding." Gottesman \& Shields $(1972,1973)$ anticipated this problem prior to the massive efforts of the past 40 years, proposing endophenotypes as a vital link in discovering and understanding genetic contributions to psychopathology.

The endophenotype concept did not get much traction (I.I. Gottesman, personal communication) until an invited review (Gottesman \& Gould 2003) provided a provocative reintroduction. By then, the traditional characterizations of psychopathology via categorical diagnoses, widely assumed 40 years ago, had come into question. The poor yield of heavily gene-focused assumptions and tactics in the psychopathology literature, now well documented (e.g., Dick et al. 2006, Kapur et al. 2012, Kendler 2005a, Miller 2010), is prompting growing interest in gene x environment $(\mathrm{GxE})$ and related phenomena. This momentum supports a convergence of the literatures on endophenotypes and on dimensional concepts of psychopathology (e.g., Cuthbert 2005, Ritsner \& Gottesman 2011, Widiger 2011) in a way that feasibly integrates psychological and biological phenomena and cuts across traditional diagnostic categories. (Present comments about GxE generally apply as well to gene-environment correlations, though they are distinct from interactions; Dick 2011, Goldhaber 2012, Thapar et al. 2007, Vrieze et al. 2012a.) The endophenotype construct is alive, well, and evolving, as this review will discuss. 
Grounded in the state of the art in animal and human research on normative cognition, motivation, and social behavior, the leadership of the National Institute of Mental Health (NIMH) has launched the Research Domain Criteria (RDoC) project, identifying several domains as near-term priorities (Cuthbert \& Insel 2010b, Sanislow et al. 2010). In the RDoC view (Cuthbert \& Insel 2010a, p. 312), "The idea is to start by specifying basic dimensions of functioning, and their implementing brain circuits, that have been identified by the last several decades of research in brain and behavior. Then, in this light, mental disorders are considered as extremes at one or both tails of these normal distributions." A central challenge that the RDoC project offers the psychopathology literature is that $\mathrm{RDoC}$ foregrounds dimensional notions, whereas the mainstream psychopathology literature has pervasively assumed that disorders are categorical - the binary diagnoses Dick (2011) alluded to (see also Frances \& Widiger 2012, Hyman 2010, Morris \& Cuthbert 2012). Whether the most generative RDoC-inspired (or endophenotypic) phenomena are best thought of dimensionally and whether the disorders for which they are endophenotypic are dimensional are separate questions. Both $\mathrm{RDoC}$ and the endophenotype approach are ultimately agnostic about dimensions versus categories, but both are entirely comfortable with the former and thus a challenge to the fully categorical model of the Diagnostic and Statistical Manual of Mental Disorders (DSM; Am. Psychiatr. Assoc. 2000) and the International Classification of Diseases (ICD; World Health Organ. 2010).

The core phenomena of psychopathology span the pessimism and exaggerated self-blame of depression, the worry or panic of anxiety, the cognitive slippage of schizotypy, the craving of addiction, the energy of mania, the remorselessness of psychopathy, and the delusions, affective dysregulation, and memory distortions seen in various disorders-all psychological phenomena and all representable dimensionally. An individual's physical, biological, and social environments provide crucial context, but psychopathology is not a property of those environments; rather, it is a property of an individual's psychology in those contexts.

In contrast to this understanding of psychopathology as in the domain of psychological phenomena, in recent decades there have been widely accepted assertions that one or another type of psychopathology is actually a brain or biochemical disorder, not a psychological disorder. Such claims confuse the nature of psychopathology with the premise that important biological phenomena occur in connection with psychopathology (Miller 1996, 2010). This misunderstanding can be seen as an overcorrection in response to the attempt a few decades earlier to locate psychopathology almost exclusively in the social, political, and economic environment. That earlier approach confused important environmental factors with the individual psychopathology it may foster, and it paid too little attention to biological (including genetic) factors. Physical, biological, psychological, social, and economic contexts are not entirely interreducible, though conceptual linkages might be developed (Kozak \& Miller 1982, Patrick et al. 2012). As discussed at length elsewhere, it may very well be that prevention or intervention efforts in one domain lead to reduced pathology in another domain, but we should not confuse the domains:

Perhaps the psychological and the biological are logically distinct domains of explanation without the respective phenomena actually being physically distinct. Or perhaps psychological and biological concepts are not merely different terms for the same phenomena (with interreducible meanings) psychological and biological explanations are not explanations of the same things. This possibility can be entertained without embracing dualism. No one accuses computer scientists of dualism due to distinguishing software and hardware or algorithm and implementation. (Miller 2010, p. 736)

It is common to conceive of psychopathology as the result of a causal chain. To prevent, predict, alter, or understand psychopathology, we turn to the links we suppose to be earlier in 
the chain. Not only do we assign causal precedence to prior links; earlier links may come to seem more fundamental than those we originally wished to affect. The temptation is to assume that the earlier in the chain we can intervene, the more powerful and effective our interventions. This appealing temptation ignores the possibility of later, more effective interventions reflecting differential feasibility or knowledge about different stages.

If instead of a single element or chain of elements, one's explanatory metaphor is a nomological network, then the opportunities for effective intervention quickly multiply, though it may no longer be obvious where the best point of intervention lies. In fact, in complex systems there may be many effective points, or none, considered in isolation. Such an explanatory network can be conceived as an indefinite set of relationships of mutual influence. Eventually any notion of serial causation dissolves into an appreciation of patterns of regularities, and that may suffice for successful science and clinical practice (Miller 2010). Unidirectional causation, like homuncular intention, is no longer needed in one's theory.

The concept of endophenotype warrants such an evolution. Commonly an endophenotype is placed between genes and behavior in a simple causal chain. Clearly, science must simplify to proceed, but it must occasionally remember that it is working with simplifications. Once in a while it must revisit and undo some of the simplifications. Such a reversal is underway in recent literature on the role of endophenotypes in psychopathology.

Even if, for the sake of simplicity, we retain some local, linear causal notions, we understand that sets of such relationships are reciprocal, even recursive. The recent progress in genomics and epigenetics (for accessible introduction, see Goldman 2012) illustrates that genes do not simply set the stage, creating a fixed biology and channeling logically subsequent environmental input, which as Kendler (2011) noted is often mistakenly assumed. For example, Laland et al. (2010; see also Goldhaber 2012) argued that human culture has powerfully affected human evolution, with hundreds of genes having been subject to rapid selection pressure due to culture. Turkheimer et al. (1995, p. 149) emphasized that "human behavioral phenotypes are, if anything, several orders of magnitude more complex than heart disease." Kendler (2005a, p. 1250) noted that "The use of the phrase 'a gene for' implies (and in fact only makes sense in the context of) genes which... 'code for' psychiatric illness in a simple, direct, and powerful way" but that "The strength of association between individual genes and psychiatric disorders is weak and often nonspecific. Genes do not appear to contain all the information needed for the development of psychiatric illness, since environmental factors have, for several disorders, been shown to have causal specificity. . . the impact of individual genes on risk for psychiatric illness is small, often nonspecific, and embedded in causal pathways of stunning complexity... Although we may wish it to be true, we do not have and are not likely to ever discover 'genes for' psychiatric illness."

Dick (2011) explored at length (see also Goldman 2012, Kendler 2011, Thapar et al. 2007) how the contribution of genes, endophenotypes, or any other contributors may not be simply to foster psychopathology. She discussed various forms of GxE interactions wherein a given allele may foster psychopathology in one environment but be a protective factor in another. Unfolding environment does not merely combine additively with pre-existing genome to drive behavior. Environment controls the operationalization of the genome, and in fact dynamic combinations of genetic and environmental nodes correlate and interact. Work by Meaney (2001) and others, the implications of which are still not yet widely appreciated (for an accessible introduction, see Goldman 2012), showed that behavior and experience in one generation alter gene expression (and behavior and experience) in a subsequent generation (and in the next hour of the individual's life). Rather than the common implicit view of a linear chain of incremental causation from a genetic fundament, a re-entrant network of relationships produces clinical phenomena. Putative endophenotypes are often presented as merely a stage inserted in a 
simple, serial, causal model, but in fact the concept is quite compatible with such a network view.

The concept of endophenotypes has become pervasive in the psychopathology research literature. This review critically surveys its impact over its first 40 years, examines its evolution in light of the growing interest in dimensional approaches to psychopathology manifested in the NIMH RDoC initiative, and considers some policy implications of endophenotypes when seen as key elements of an explanatory network for psychopathology.

\section{THE ENDOPHENOTYPE CONCEPT}

Gottesman drew from insect genetics thanks to his PhD mentor, Sheldon Reed, a Drosophila specialist who encouraged him to pursue human twin studies (I.I. Gottesman, personal communication). In bringing the concept of endophenotype to the psychopathology literature, Gottesman \& Shields $(1972,1973)$ borrowed and broadened the term from the work of John \& Lewis (1966, p. 720), who had explained that "The endophenotype, by definition, does not affect the competitive efficiency or, therefore, the adaptedness of the individual; it affects the number and nature of the offspring. . . It is our hope that this review will serve to show that, as far as the study of geographical distribution in insects is concerned, it is clearly time to examine more fully not the exophenotype but the endophenotype, not the obvious and external but the microscopic and internal, not the genic but the chromosomal." Gottesman \& Shields $(1972,1973)$ were not proposing that psychopathology researchers leap immediately to the chromosomal level, but their work strongly advocated bringing genes into the picture.

Specifically, introducing the endophenotype concept to the psychopathology literature was in the service of two major goals: to identify the genes that contribute to psychopathology and to identify the mechanisms by which genetic inputs translate into biological and psychological processes (including psychopathology) manifest in the phenotype. Central to the proposal was their wager that endophenotypes are driven by fewer genes than the full, complex phenotypic disorder, although more recent theorists have begun to challenge whether genetic and $\mathrm{GxE}$ contributions to putative endophenotypes will turn out to be substantially simpler than those to traditional disorders (e.g., Cannon \& Keller 2006, Dick 2011, Kendler 2011, Turkheimer 2000, White \& Gottesman 2012). For example, psychological traits can have a very substantial genetic input even without individual genes having large effect sizes. Still, there is good reason to look for fundamental psychological and biological processes rather than to work only with whole disorders and work upstream to find their sources.

Gottesman \& Shields $(1972,1973)$ left room for complex relationships, suggesting a role of endophenotypes as a bridge between various levels (symptoms, genes, behavior, psychological processes, brain structure, brain chemistry, and their variation with environmental influences). Their hope was that discovering bidirectional, correlative relationships between endophenotypes and phenomena at diverse levels would point to the mechanisms of translation along the causal path from origin (genetic and otherwise) to phenotype.

The endophenotype concept was novel and generative at a time when the urge to understand mental disorder was insufficiently satisfied by numerous findings of relationships between diagnoses and more specific measures of abnormality (symptom, performance, psychological deficits, etc.) on one side and the emerging evidence of heritability of disorder on the other. It should be noted that circa 1970 the case for a very substantial genetic contribution to psychopathology was just forming (e.g., Gottesman 1963, Gottesman \& Shields 1967, Heston 1970, Kety et al. 1968, Meehl 1962). Prompted by the introduction of the concept of endophenotypes and research guidelines for their identification, enthusiastic and ambitious 
research efforts identified many candidates but also challenges, caveats, and limitations, discussed below.

Forty years in, at the end of what we might call the Decade of the Endophenotype that began with Gottesman \& Gould's (2003) seminal update to the endophenotype enterprise-now with a huge body of research, an intense conceptual discussion, and diverse methodological progress in genomics and neuroscience in hand-where does the concept of endophenotype stand? Does the record support expectations that endophenotypes can be reliably identified or that they reduce the gap between observed relationships between diagnoses, more specific measures of pathology, and growing evidence of heritability from behavioral studies and molecular genetics? Does it support the assumption of a profound genetic contribution to mental disorder? Does the record facilitate specification of mechanisms?

This review discusses advantages and benefits as well as conceptual and methodological challenges of and constraints on endophenotype research by evaluating three contentions:

1. Endophenotypes are useful for understanding the origins of mental disorder.

2. Endophenotype research supports a transdiagnostic perspective on mental disorder.

3. Multivariate, multilevel approaches encourage a change from a single causal chain to a network metaphor.

\section{DEFINING THE ENDOPHENOTYPE}

In the original conceptualization, Gottesman \& Shields (1973, p. 19) characterized endophenotypes as "internal features. . only knowable after aid to the naked eye. . by a biochemical test or a microscopic examination." This has commonly been read to mean that they conceived endophenotypes as necessarily biological phenomena. Paris (2011, p. 260) described the naive reductionism common in this literature: "It has been suggested that psychiatric diagnosis should come to depend on endophenotypes, in order to define more precisely the mechanisms behind mental disorders. This construct is associated with the assumption that mental processes can be reduced to activity at a neuronal level."

Gottesman \& Shields (1972) did not make that assumption. Of course, biological phenomena are not necessarily genetically driven, in the sense of where the interesting variance comes from, but the endophenotype notion is even less restrictive. Although the literature on endophenotypes has commonly assumed that they must be biological (in the sense that a direct measurement of a biological phenomenon is required), Gottesman has never limited the concept to biological phenomena (I.I. Gottesman, personal communication; Lenzenweger 2010). For example, personality inventory profiles could qualify as endophenotypes. This was explicit from the beginning: "We are optimistically hopeful that the current mass of research on families of schizophrenics will discover an endophenotype, either biological or behavioral (psychometric pattern)..." (Gottesman \& Shields 1972, p. 336).

In the first two decades following the original proposal, various investigators proposed criteria for an endophenotype or related notions of genetic markers (for discussions of criteria, see Cannon \& Keller 2006; Iacono 1982, 1983, 1985; Iacono \& Lykken 1979; Iacono \& Malone 2011; Turetsky et al. 2007). In 2003, Gottesman \& Gould (p. 636) characterized endophenotypes as "measurable components unseen by the unaided eye along the pathway between disease and distal genotype" and called endophenotypes "simpler clues to genetic underpinnings than the disease syndrome itself." Gould \& Gottesman (2006, p. 115) affirmed that the core idea of an endophenotype was unchanged: "Endophenotypes represent more defined and quantifiable measures that are envisioned to involve fewer genes, fewer interacting levels and ultimately activation of a single set of neuronal circuits. ..". 
Gottesman and colleagues (Hasler et al. 2006, p. 93) emphasized that in their conceptualization, the endophenotype "fills the gap in the causal chain between genes and distal diseases," and they added some flexibility to the state-independence or stability criterion, offering these criteria (Hasler et al. 2006, p. 94; see also Ritsner \& Gottesman 2011):

1. An endophenotype is associated with illness in the population.

2. An endophenotype is heritable.

3. An endophenotype is state independent (manifests in an individual whether or not illness is active) but age normed and might need to be elicited by a challenge (e.g., glucose tolerance test in relatives of diabetics).

4. Within families, endophenotype and illness cosegregate.

5. An endophenotype identified in probands is found in their unaffected relatives at a higher rate than in the general population.

Gottesman and colleagues have updated the endophenotype discussion in several important ways in the past decade. Chan \& Gottesman (2008, p. 962) added a sixth criterion: "The endophenotype should be a trait that can be measured reliably, and ideally is more strongly associated with the disease of interest than with other psychiatric conditions (i.e., specificity) (cf. Hasler et al. 2006)." Hasler et al. (2006, pp. 94-95) conveyed mixed feelings about the specificity issue: "It should be emphasized, however, that endophenotypes, reflecting genetically relevant aspects of the heterogeneous pathophysiology of the disease, are clearly different from diagnostic markers, which are evaluated by measures of sensitivity and specificity, because it cannot be assumed that the current definitions of psychiatric diseases are biologically valid. Claiming biological and clinical plausibility as endophenotype criteria prematurely or a priori might consequently impede discoveries of novel, unexpected disease mechanisms. We are not yet able to carve nature at its joints because we are uncertain as to what are the joints." Although no one could argue with the value of reliability of measurement, Hasler and colleagues were identifying two important caveats for evaluating candidate endophenotypes that the literature has largely ignored. First, biological plausibility can be demanded too early and too stringently. Second, defining clinical plausibility in terms of conventional categorical diagnoses can be very problematic. We return to both issues below.

Hasler et al. (2006, p. 95) also articulated a notion of a "pheno-geno gradient of endophenotypes" and noted that "relatively broad endophenotypes (brain function endophenotypes, e.g., cognitive performance) might be the most heritable and most appropriate for genetic studies." This view of a gradient on which endophenotypes differ in their distance from both genes and clinical manifestations is compatible with the more elaborate notion of a network of relationships within and around endophenotypes proposed by Cannon (2005), to which we also return below.

Other scholars have largely adopted the view of Gottesman and colleagues. Cannon \& Keller (2006, p. 267) described the endophenotype approach as an "alternative method for measuring phenotypic variation that may facilitate the identification of susceptibility genes for complexly inherited traits" (see also Archer et al. 2011). Turetsky et al. (2007, p. 69) more directly connected endophenotypes to "the actions of genes predisposing an individual to a specific disorder, even in the absence of any diagnosable pathology." A number of interesting corollaries have been derived from the basic notion, such as that relevant genes ought to correlate better with the endophenotypes than with the manifest disorders (Flint \& Munafo 2007; for other important corollaries, see Kendler \& Neale 2010). A particularly sensible extension of the Gottesman \& Shields (1972) criterion that the endophenotype must be associated with the disorder in the population is that it must be associated with causes and not merely effects of the disorder (Cannon \& Keller 2006), though Kendler \& Neale (2010) noted that tests of this criterion are vulnerable to differences in measurement error and that it is not uncommon to find that the genetic influence on the putative endophenotype is smaller than that on the disorder. 
Despite general consensus about the endophenotype concept, three differentiators of these concepts can be noted. First, the Gottesman et al. concept has historically assumed a genetic input, but it has not required that the genetic contribution to a given endophenotype be the most prominent. One can readily imagine an endophenotype that is so driven by environmental contributions or whose gene $\mathrm{x}$ environment or gene-environment correlation contributions are so far removed from simple, Mendelian genetic models that the genetic grounding is but a small part of the story. However, some authors portray endophenotypes as being essentially manifestations of wholly genetic contributions. That is a misunderstanding of the concept.

A second differentiator is that the Gottesman et al. concept was framed as having biological validity, but as discussed above endophenotypes themselves need not be biological, such as a working memory deficit (Cannon \& Keller 2006, Hasler et al. 2006, Manoach 2003) or accuracy and speed across a battery of cognitive tests (Gur et al. 2007a,b) in schizophrenia, a memory bias in depression (Levin et al. 2007), cognitive bias (MacLeod \& Mathews 2012) or attentional deficit in anxiety (Sass et al. 2010), impaired decision-making associated with suicidal behavior (Courtet et al. 2011)—all phenomena that are definitionally psychological. De Geus \& Boomsma (2001) listed 18 behavioral tasks as "behavioral endophenotypes of cognition" and implied that many more are available (though they did not undertake to review how many of these have been shown to meet full Gottesman criteria for an endophenotype).

Although for the endgame Hasler et al. (2006) included biological validity for endophenotypes, they did not confine endophenotypes themselves to biological phenomena. Specifically, they proposed that endophenotypes could be phenomena in any domain. Their view was that endophenotypes do not have to be biological phenomena but are "biologically valid"- consistent with genetic and other biological contributors. NIMH RDoC policy (Insel \& Cuthbert 2009, p. 988) embraces this broader view: "Endophenotypes are relatively well-specified physiological or behavioral measures that are considered to occupy the terrain between disease symptoms and risk genotypes."

In a paper specifically designed to avoid any ambiguities in the definition of endophenotypes by emphasizing the difference between biomarkers in general and that subset that is heritable (I.I. Gottesman, personal communication), Gould \& Gottesman (2006, p. 113) wrote: "Endophenotypes can be neurophysiological, biochemical, endocrine, neuroanatomical, cognitive or neuropsychological." In Hasler et al. (2006), Gottesman and colleagues mentioned "cognitive performance" as a potential endophenotype. Cannon \& Keller (2006) cited "cognitive dysfunction" as a potential class of endophenotypes. Ritsner \& Gottesman (2011) listed a series of psychological deficits as endophenotypes relevant to functional psychoses. Robbins et al. (2012) proposed impulsivity and compulsivity as endophenotypes. Thus, endophenotypes do not have to be directly biological phenomena, even though "the endophenotype approach assumes that the underlying liability of endophenotypes represents basic biological phenomena" (Hasler et al. 2006, p. 95). Endophenotypes do have to meet the criteria Gottesman and colleagues have articulated, unless an author explicitly discusses alternative criteria employed.

Walters \& Owen (2007) and Kendler \& Neale (2010) noted that one could fruitfully conceive of an environmental endophenotype, which could foster liability to disorder in some direct way or mediate the influence of another endophenotype, or an endophenotype that itself captured some combination of genetic and environmental contributions. In fact it is entirely reasonable to understand endophenotypes as subject to the same $\mathrm{GxE}$ factors and gene-environment correlations as is commonly assumed for traditional categorical disorders. This broader framing does not render the concept of endophenotype uselessly inclusive as long as the defining requirements such as heritability are retained. It does reflect the principle that we should try to identify and explain phenomena that are causally close to other phenomena before we try to engage longer explanatory 
chains. Biological, psychological, and environmental phenomena may all qualify for roles in an account of mental illness. Meehl (1977) noted that we tend to characterize a disorder as distinctly a genetic, dietary, psychological, etc. disorder if we believe that that one domain provides the most important (perhaps the most differentiating) contribution - the specific etiology. It now appears that genes alone cannot achieve that designation in mental illness.

A third differentiator of the endophenotype and related concepts is that the role of a given phenomenon in an account of a disorder may or may not be causal. "Endophenotype" has been rather carefully defined (especially by Gould \& Gottesman 2006), but not all usage is in line with the definition. Although here and elsewhere we have argued against framing psychopathology as inherently biological and have suggested that the present state of the literature makes any assumption about causal direction in biology-psychology relationships premature at best (Miller 1996, 2010; Miller \& Keller 2000), the present review does not advocate straying from the Gottesman conceptualization of endophenotypes as phenomena located along an explanatory path to disorder. However, in evaluating the impact of the endophenotype concept, it is important to recognize that writings that invoke the term "endophenotype" vary substantially in how and how much they stray.

Related but looser terms such as a "biomarker" for, a "biological substrate" of, or phenomena said to "underlie" a disorder vary greatly in their usage in the literature (see Iacono 1983 for an early discussion of this problem and Lenzenweger 2010 for an especially thoughtful critique). Biomarkers are sometimes viewed as merely correlates, sometimes as necessary (though not sufficient) signs, and sometimes as mere epiphenomena. Lenzenweger (2010) noted that a biomarker need not meet the heritability criterion required of an endophenotype. Ritsner (2011) distinguished risk factors, endophenotypes, and putative neurobiological factors. Kendler \& Neale (2010) questioned whether biomarker is even an appropriate term for a genetic correlate of disorder. Biological risk indicators can be mere correlates, whereas an endophenotype is a mediator (Kendler \& Neale 2010). "Intermediate phenotype" is closer to the endophenotype concept and is sometimes viewed as a synonym for it (e.g., Cannon 2005, Glahn et al. 2010, Hill 2010, Insel \& Cuthbert 2009, Kendler \& Neale 2010, Preston \& Weinberger 2005), but Lenzenweger (2010) provided an extended and compelling criticism of "intermediate phenotype" in this context. "Latent phenotype" (Sabb et al. 2009) is essentially the same notion. White \& Gottesman (2012) equated endophenotypes only with heritable intermediate phenotypes. Gottesman and colleagues (Courtet et al. 2011, Gottesman \& Gould 2003) have criticized these terms as failing to distinguish cause from effect, again leaving them open to the criticism of being epiphenomenal. Epiphenomena can be informative but will generally not be as explanatory.

This variability in usage renders difficult judgments about whether phenomenon $X$ "is" an endophenotype (or biomarker or whatever). Numerous papers claim that result $X$ "could be a biomarker" for disorder $Y$. Without substantive explication of a nomological net around such a finding, which is very often missing, there is essentially no information value in such statements (see also Gotlib \& Hamilton 2012, Kozak \& Miller 1982, Patrick et al. 2012). Gould \& Gottesman (2006, p. 114) dismissed biomarkers as merely biological measures associated with some populations: "Among studies of psychiatric diseases, there exists an overwhelming number of biological markers. However, these often solitary findings frequently have limited reproducibility, both among and within patients, and may represent state dependent results."

As noted above, the criteria for endophenotypes have evolved slightly, and the concept has been clarified in the past decade. Clinical evidence in schizophrenia and other disorders that become manifest during development, for example, challenged the criterion of state independence as mandatory and suggested allowing changes during active stages of brain maturation in adolescence and early adulthood (Pantelis et al. 2010). Iacono \& Malone (2011) cited a variety of sets of 
criteria, provided a particularly detailed set, and emphasized that developmental considerations have received too little attention in prior literature. As noted above, Gottesman and colleagues embraced this point in modifying the state-independence criterion (Hasler et al. 2006; see also Vrieze et al. 2012a). Some authors have emphasized that a one-to-one mapping of endophenotype to disorder should not be assumed or sought. Cannon \& Keller (2006; see also Gilmore et al. 2010b, Kendler \& Neale 2010) noted that a given disorder could be affected by numerous endophenotypes and that conversely a given endophenotype could affect multiple disorders. This proposal seems particularly credible and generative for disorders with multiple genetic contributors, which is now increasingly suspected (e.g., Dick 2011, Gould \& Gottesman 2006, Kendler 2011). Indeed, for at least many disorders, "multiple molecular entry points to illness liability" have to be assumed (Eisenberg \& Berman 2010, p. 258). Cannon \& Keller (2006) also suggested that endophenotypes should vary continuously (dimensionally) in the general population and should optimally be measured across several levels of analysis.

Further proposed extensions of the endophenotype concept or criteria have recommended that they be assessed by experimental, laboratory-based methods rather than by clinical observation (Pearlson \& Folley 2008) so that measurement would be "rapid and easy ... in growing recognition of the necessity of large samples for well-powered analyses" (Turetsky et al. 2007, p. 70), given that individual contributions to variance will likely be quite small, that adequate test-retest reliability and between-site reliability should be assured, and that performance impairments should be shown not to be due to medication (Gur et al. 2007a). Turetsky et al. (2007) recommended that an endophenotype candidate reflect a "discrete and well-understood neurobiological mechanism that is both informative for the pathophysiology of a disorder and indicative of the action of a limited number of genes" (p. 70). When considering such a criterion, one can differentiate whether $(a)$ identifying the relevant biological mechanisms should be required before classifying a phenomenon as an endophenotype versus $(b)$ viewing classification of a phenomenon as an endophenotype augurs well for later identifying the relevant mechanisms, including biological mechanisms. Hasler et al. (2006, p. 95) argued against adding biological or clinical plausibility to endophenotype criteria, as these could "impede discoveries of novel, unexpected disease mechanisms." They also did not favor evaluating candidate endophenotypes for sensitivity or specificity as diagnostic markers for clinical diagnosis "because it cannot be assumed that the current definitions of psychiatric diseases are biologically valid."

A final caveat for defining and studying endophenotypes is that the issue of statistical power is receiving increasing attention in the endophenotype and neighboring literatures as it becomes appreciated that many genome-motivated studies have been seriously underpowered (e.g., Dick 2011, Duncan \& Keller 2011, Kendler 2011, Lenzenweger 2010, Turetsky et al. 2007). Roberts et al. (2007) noted that small effects are common in many contexts and may in any case have substantial practical significance.

Indeed, what constitutes an adequate power analysis seems often to be misunderstood. Commonly in grant applications, for example, a power analysis is offered based on the assumption that an effect size will approximate that found in some other study. But such a benchmark is usually of little value. A host of factors could render an effect larger or smaller in another sample assessed in a different context. Ideally, a point prediction of effect size would be offered based on quantitative understanding of the phenomenon (Meehl 1978). Unfortunately, good grounds for such a stance are rarely available in psychopathology research, but the question of what would be an adequate test of the hypothesis should nevertheless be engaged. Pragmatically, how small an effect should the study be powered to find? What is needed is a clear stand on how small an effect is worth finding, not how big an effect is likely (Miller 2004). Until the issue of effect size is more realistically and successfully engaged, we are left with the observation that, in general, 
behavior genetics studies-typically pooling and thus not distinguishing the roles of numerous genetic contributions-have proven much more replicable than have molecular genetics studies focusing on specific genes (Kendler 2011).

\section{PROGRESS AND PROMISE: THREE CONTENTIONS}

Now at the end of what above we called the Decade of the Endophenotype, a long roster of publications are available that claim to have demonstrated an endophenotype for disease $X$ or that advocate measure $Y$ as a promising candidate for an endophenotype. (Rarely does a thorough evaluation against the criteria of Cannon \& Keller 2006, Hasler et al. 2006, Iacono \& Malone 2011, etc., accompany such a stance.) Progress, promise, and take-home outcomes for some proposed endophenotypes have been carefully reviewed and evaluated in that decade (e.g., Cannon 2005, Cannon \& Keller 2006, Flint \& Munafo 2007, Gotlib \& Hamilton 2012, Gottesman \& Gould 2003, Iacono \& Malone 2011, Insel \& Cuthbert 2009, Kendler \& Neale 2010, Preston \& Weinberger 2005, Walters \& Owen 2007). Reviews have addressed whether and to what extent research evidence has lived up to the goals of facilitating study of genetic contributions to disorder and identifying endophenotypes that are grounded well enough to be useful in this respect.

The abundance of studies and diversity of results may reflect challenges inherent in endophenotype research. Most fundamentally, thorough consideration of criteria proposed for endophenotype identification exceeds capabilities of most laboratories (e.g., longitudinal, multisite-population studies that integrate molecular genetics, neuroscience, and cognitive assessment). Even ambitious, longitudinal studies may not allow adequate examination of the stateindependence criterion, given ongoing variance in gene expression, such that many phenomena that may depend greatly on genes vary over time.

But much has been accomplished. The present selective review discusses several endophenotypes for which a solid body of evidence is now available. The agenda is less to pass judgment on specific endophenotypes and more to determine what such progress tells us about the promise of endophenotype research regarding implications for future research and policy, by examining (a) the usefulness of endophenotypes for understanding disorder, $(b)$ the usefulness of endophenotypes for binary (present/absent) diagnoses versus transdiagnostic dimensional characterization, and $(c)$ the usefulness of multivariate, multilevel methods supporting a network conceptualization of endophenotypes.

The emphasis here is on schizophrenia as the disorder most intensely pursued for endophenotypes, and on executive functions, sensory gating, and eye movement disorders (EMDs) as exemplar domains of endophenotypes for which substantial evidence is available (see also the special section on endophenotypes in schizophrenia that appeared in the first issue of Schizophrenia Bulletin in 2007 and a review by Lenzenweger 2010). Other reviews document substantial endophenotype research for other disorders: Hasler et al. $(2004,2006)$ considered potential psychological and biological endophenotypes in major depression and bipolar disorder. Hasler \& Northoff (2011) proposed neuroimaging-based endophenotypes for major depression. Ritsner \& Gottesman (2011) reviewed endophenotypes for schizophrenia and bipolar disorders as types of "functional psychoses." Courtet et al. (2011) and Mann et al. (2009) agreed that impulsivity appears to meet all traditional criteria for an endophenotype of suicidal behavior, and both papers reviewed other promising candidates with some or very considerable supporting evidence. Dick et al. (2006) reviewed a series of studies showing successful uses of an electroencephalography (EEG) endophenotype to identify candidate genes in risk for alcoholism. Robbins et al. (2012) discussed impulsivity and compulsivity as endophenotypes for a variety of traditional diagnoses. Hill (2010) noted a number of endophenotypes she judged valid for alcoholism. Iacono \& Malone (2011) provided a particularly thorough 
and compelling evaluation of the P300 component of the visual stimulus event-related brain potential as an endophenotype for genetic vulnerability to externalizing disorders. Siever (2005) and Reichborn-Kjennerud (2010) discussed potential endophenotypes for personality disorders.

\section{Endophenotypes Are Useful for Understanding the Origins of Disorder}

Schizophrenia has been a primary target of endophenotype research. When Gottesman \& Shields (1972) proposed the endophenotype concept, the case for genes having a major role in schizophrenia was just being accepted. Even while offering the pioneering "It is my strong personal conviction that. . schizophrenia, while its content is learned, is fundamentally a neurological disease of genetic origin," Meehl (1962, p. 837) also believed in a contribution from "schizophrenogenic mothers" (see also Meehl 1972). The endophenotype concept was offered when those who did suspect a major role for genes anticipated discoveries of single genes of moderate to large effect (Cannon \& Keller 2006, Kendler \& Neale 2010). Forty years hence, no such genes have been established, and the specific roles of genes (let alone the roles of specific genes) remain to be determined for any mental disorder. Moreover, current knowledge about specific genetic contributions to schizophrenia does not yet derive primarily from endophenotype research. Genomewide association studies (GWAS) and single nucleotide polymorphism analyses have provided substantial insight into the polygenic nature of schizophrenia together with the awareness that genetic factors in schizophrenia cannot be sufficiently identified nor mechanisms explained without better allowance for the complexity of the genetic story in schizophrenia and even larger studies undertaken in light of that (Owen 2012, Sullivan et al. 2012). How then might endophenotypes be useful for understanding schizophrenia?

The endophenotype concept has enjoyed a resurgence in the decade since Gottesman \& Gould (2003) updated the Gottesman \& Shields (1972) proposal. Findings that authors have claimed or proposed as endophenotypes identified for schizophrenia cover quite a spectrum, including diverse behavioral and neural measures. Cannon (2005) concluded that heritable dimensions of cortical and subcortical system function captured in endophenotype candidates such as executive functions, sensory gating, and eye movement can be related to candidate genes for schizophrenia (some examples noted below). Gould \& Gottesman (2006, Ritsner \& Gottesman 2011) cited the same three as qualifying as endophenotypes of schizophrenia. Reviews have recently appeared of potential endophenotypes for which the case is close but judged not yet as strong, such as Calkins et al. (2008) and Mazhari et al. (2011) regarding eye movement abnormalities, Chan \& Gottesman (2008) and Neelam et al. (2011) regarding neurological soft signs, and White \& Gottesman (2012) regarding brain connectivity and gyrification.

Executive functions have been characterized as related but somewhat distinguishable abilities or processes valuable for preparing, controlling, and evaluating one's behavior. Various taxonomies exist, commonly differentiating response inhibition/inhibitory control, updating of working memory representations, set-shifting/redirecting attention, and, often, planning and/or fluency (for overview, see Eisenberg \& Berman 2010, Friedman et al. 2008, Niendam et al. 2012). Disruption of these functions (especially inhibition and working memory) in schizophrenia has been related to dysfunction in seven brain regions (reviewed by Eisenberg \& Berman 2010; see also Pearlson \& Calhoun 2009, Walshaw et al. 2010) including dorsal and ventromedial prefrontal and anterior cingulate cortex (ACC), dopaminergic regions (Gregoire et al. 2012), and subcortical circuits. A recent quantitative meta-analysis of 193 functional imaging studies including 2,832 healthy individuals revealed a common pattern of activity in prefrontal, dorsal ACC, and parietal regions across executive function domains (Niendam et al. 2012). Additional domain-specific activity has been associated with anterior prefrontal and anterior and mid-cingulate regions. 
Such findings raise an intriguing but presently intractable question. Given that multiple brain regions are involved in multiple executive function deficits that appear to qualify as endophenotypes, what is the best degree of granularity for exploring their role in schizophrenia? Should the various regions be treated much like items on a self-report questionnaire for which we prefer high coefficient alpha? Is each an individually fallible indicator of a single latent factor that undermines function in multiple regions via a single dysfunction, in line with Meehl's (1962) proposal of a "neural integrative defect"? Or is a better metaphor a checklist of abnormalities that are largely uncorrelated in the general population but that, when they happen to coincide, cause marked dysfunction? Such was the model used in the seven-item scale of Golden \& Meehl (1979), mistakenly faulted for low internal consistency. They sought indicators that were poorly correlated in the general population but that, when coincident, greatly boosted risk.

The emergenesis concept of Lykken et al. (1992) comes to mind: a powerful coincidence of individually very rare and uncorrelated genetic factors. This hypothesis is supported by a recent evaluation of genomics progress, finding convincing support that genetic contributions to schizophrenia are more likely to be found in rare variants (copy number variations) and their de novo mutation than in specific genes (Owen 2012). Such rare genetic events could combine additively or interactively, the latter an example of epistasis, wherein one gene modifies the effect of another. Yet a third way to understand the identification of multiple affected brain regions is that the story lies not in some additive or even conventionally interactive combination of these regions but in some dynamical whole, where the key abnormality is in the network(s) they constitute, not in the individual regions. Thus, a superordinate cortical network implementing executive control could itself be an endophenotype. The literature on executive function as an endophenotype in schizophrenia is not yet able to choose among these conceptualizations of how genes contribute.

Deficient executive functions in schizophrenia patients and unaffected family members have been established in neuropsychological tests of working memory and inhibition (for overview, see Pearlson \& Calhoun 2009, Ritsner \& Gottesman 2009; for working memory, Giakoumaki et al. 2011, Glahn et al. 2003, Owens et al. 2011; for visual memory, Tuulio-Henriksson et al. 2003). Executive function was evaluated on the heritability criterion in a multivariate twin study (Friedman et al. 2008) that suggested a highly heritable common factor, with additional genetic influences accounting for additional interindividual variability in two executive composites, inhibition and updating of working memory. Eisenberg \& Berman (2010; see also Bearden et al. 2012, Munakata et al.2011) evaluated as yet inconclusive evidence of genetic contributions to normal and disrupted executive functions for nine candidate genes related to dopaminergic and glutamatergic activity and to neural network connectivity, all of which have been proposed as putative schizophrenia risk genes (Esslinger et al. 2011, Karlsgodt et al. 2011, Markett et al. 2011).

As emphasized by Eisenberg \& Berman (2010) and Owen (2012), even candidate risk gene variants that are likely to contribute only small portions of variance to a complex behavioral phenotype can be useful in conjunction with other methods. Importantly, some of the proposed candidate genes are known to affect neurodevelopment (e.g., DISC1, neuregulin1). Moreover, variation (polymorphisms, copy number variation, rare mutants) in schizophrenia has been associated with memory function and dysfunction in general (Jaaro-Peled et al. 2009, Jablensky et al. 2011, Papassotiropoulos \& de Quervain 2011). Genetic factors proposed to explain memory functions overlap with those reported for executive functions above.

The case for executive function as an endophenotype in schizophrenia is by no means monolithic, conveyed by a small sampling of mixed results. The impressive, multilevel informatics meta-analysis of Sabb et al. (2009) found genes contributing only around 7\% of the variance in memory function, despite behavior-genetic studies establishing heritability of memory of around $50 \%$. Moreover, conflicting results and lack of diagnostic specificity challenge the validity of 
working memory as an endophenotype. For example, patients and unaffected relatives showed impaired delayed verbal working memory, whereas immediate recall was intact in relatives (O'Driscoll et al. 2001). Unaffected siblings or parents and unrelated healthy subjects did not differ in their performance on the California Verbal Learning Test (Stone et al. 2011). Pearlson \& Calhoun (2009) cited task-dependent performance variation that could undermine working memory as an endophenotype. Lennertz et al. $(2011 \mathrm{a}, \mathrm{b})$ demonstrated via GWAS that a polymorphism of a transcription factor (TCF4) usually associated with mental retardation was related to risk for schizophrenia but also to verbal working memory (the latter actually being better in schizophrenia carriers of the gene variant). Thus, the TCF4-mediated schizophrenia risk is not determined by the TCF4 effect on memory.

On balance, a considerable literature supports viewing executive function as an endophenotype for schizophrenia. But executive function is an enormous construct, much in need of deconstruction in order to identify its role(s) in and sensitivity and specificity for the etiological path(s) to schizophrenia. Such a broad psychological construct is likely to have numerous genetic contributors and thus to warrant a recursive analysis: identification of endophenotypes for executive function itself. Focusing some endophenotype research upstream, on more basic concepts such as sensory integration, neuroplasticity, and connectivity (Bullmore 2012, Owen 2012, White \& Gottesman 2012), is warranted.

Sensory gating is a much narrower phenomenon apparently earlier in the causal path(s) to schizophrenia. It has been studied extensively as a potential endophenotype in schizophrenia. Sensory gating is usually evaluated using one of three phenomena: prepulse inhibition (PPI), P50/M50 suppression in the electromagnetic response to the second of paired clicks (some authors add or prefer N100/M100 suppression), and acoustic startle. Abnormal P50 response is a particularly robust candidate, the only biological measure ranking among the top ten effect sizes in meta-analyses of schizophrenia deficits (e.g., Heinrichs 2004). Cannon \& Keller (2006, p. 264) concluded that "together with abnormal gating of the P50 electrophysiological response to repeated stimuli, deficits in frontal and temporal lobe memory systems are also the endophenotypes showing the strongest evidence of linkage and/or association with genetic polymorphisms previously shown to be associated with schizophrenia." We briefly discuss the first two of these measures of sensory gating, as there is very little literature on acoustic startle as a potential endophenotype.

PPI and P50/N100 suppression meet criteria for a robust quantitative measure, reliably related to diagnosis, with established regulating brain circuits (frontal, limbic, and mesolimbic; for PPI, see Swerdlow et al. 2008; for P50/M50/N100/M100, see Rosburg et al. 2008, Smith et al. 2010, Turetsky et al. 2008, Williams et al. 2011). Polymorphisms in serotonin and dopamine system genes, COMT, neuregulin-1, DISC, and NMDA-related genes have been found to vary with PPI (Petrovsky et al. 2010, Powell et al. 2009, Quednow et al. 2009). P50 suppression has been related to the COMT polymorphism (Ancin et al. 2011, Lu et al. 2007). These genes have also been related to schizophrenia risk, notwithstanding a need for caution because of high variability and polygenetic contributions. Sensory gating measures vary with medication and clinical state, so the state-independence criterion for qualifying as an endophenotype is not consistently fulfilled. As noted above, that criterion has been questioned by many and softened by some in the endophenotype literature. For example, endophenotypes need not be invulnerable to cognitive training or medication. An intervention might alter not only a manifest symptom but the psychological or biochemical mechanisms that drive it, and some of those mechanisms may be endophenotypes.

More problematic is that even though sensory gating is a far simpler construct than executive function, once again its facets show significant divergence that complicates pursuit and interpretation of it as an endophenotype. PPI is not consistently related to P50 suppression or acoustic startle (Swerdlow et al. 2008), so it is not clear what aspect(s) of sensory gating ought to qualify 
as an endophenotype. Moreover, candidate gene variants have not always been found to associate with P50 suppression across psychotic patients, unaffected relatives, and healthy subjects (Shaikh et al. 2011). Finally, substantial variability and overlap in PPI distributions among patients with different disorders (such as schizophrenia, autism, and obsessive-compulsive disorder) and healthy subjects (Braff et al. 2007, Swerdlow et al. 2008) temper the case for the PPI variant of sensory gating contributing to the understanding of schizophrenia.

The NIMH RDoC initiative, however, sets the stage for reevaluating such diagnostic nonspecificity as providing transdiagnostic, possibly dimensional evidence that PPI sensory gating is nevertheless an endophenotype. This is supported by the comparison of schizophrenia and bipolar disorders (Ritsner \& Gottesman 2011). Swerdlow et al. (2008, p. 376) concluded that "The construct of gating deficits in neuropsychiatric disorders has empirical support and intuitive appeal, and serves as a unifying heuristic for understanding the psychological and neural substrates shared by otherwise unrelated disorders. PPI is an operational measure of basic, brain-based gating processes. It is robust, reliable, easily quantified, and versatile as an experimental tool, and is abnormal in several brain disorders including schizophrenia that are characterized by clinical evidence of impaired gating."

In summary, whereas there is strong evidence that sensory gating qualifies as an endophenotype for schizophrenia, it needs further explication to foster discovery of its role(s). It is telling that, despite the apparent simplicity of sensory gating relative to executive function, it has proven to be quite challenging to narrow the construct to the most useful framing for mechanism discovery. As with detailing the human genome, identifying an endophenotype is not the ultimate goal.

Comparing the state of the literatures for executive function and sensory gating also prompts consideration of the challenge and potential value of identifying relationships among endophenotypes. Recent evidence indicates a role for frontal cortex in auditory sensory gating (Chen et al. 2012, Williams et al. 2011), even though it has long been assumed that cortex in or near Heschl's gyrus is the cortical locus for sensory gating and its impairment in schizophrenia (e.g., Edgar et al. 2008, Popov et al. 2011, Smith et al. 2010). Once again the literature implicitly directs us to network phenomena at both psychological and neural levels.

Many investigators have evaluated eye-movement abnormalities as a potential endophenotype for schizophrenia (Iacono 1998). Calkins et al. (2008) and Mazhari et al. (2011) provided reviews of saccade movement abnormalities as an endophenotype. Calkins et al. (2008, p. 456) commented, "Despite the promise of endophenotypes, relatively few researchers have attempted to apply EMD endophenotypes to molecular genetic studies. The results of studies that have ventured into this domain have been intriguing but thus far limited to a few specific candidate endophenotypes and genes. Yet, this kind of research can advance schizophrenia research by merging two fields: molecular genetics, which is in need of more genetically homogenous groups, and endophenotype research, which is in need of genetic underlying apparently heritable indicators of schizophrenia risk. The actualization of the promise of endophenotypes to assist in the schizophrenia gene hunt, as yet largely unfulfilled, will rest on further research seeking to explicate the relationships among genes and candidate endophenotypes like EMD."

The first of three contentions under review here is that endophenotypes are useful for understanding the origins of mental disorder. As noted previously, the present discussion has undertaken a selective review, not to provide a settled judgment about specific candidate endophenotypes but rather to evaluate the overall progress and promise of the endophenotype concept. The study of endophenotypes can serve at least two distinct purposes (Walters \& Owen 2007): identification of risk genes and identification of the functional consequences of such genes. The literature has not yet met either of those goals. In the case of schizophrenia, quite a bit has been accomplished in service of those goals, in that there is considerable consensus that executive function and sensory 
gating qualify as endophenotypes, and the case is close for eye-movement dysfunction. For externalizing disorders, P300 amplitude reduction is a convincing endophenotype (Iacono \& Malone 2011). But endophenotype-oriented research has not definitely identified specific genes or specific mechanisms relating genes to endophenotypes or endophenotypes to disorders. Given that no other type of psychopathology research has achieved those goals, the fault would not appear to lie specifically with the endophenotype concept. Still, it seems unlikely that many candidate endophenotypes that themselves reflect numerous genetic inputs have much chance of pointing the way to specific genes. For the potential gene-finding benefit of endophenotype research, we may need to pursue endophenotypes for some of the endophenotypes.

\section{Endophenotype Research Supports a Transdiagnostic Perspective on Mental Disorder}

The endophenotype literature has tended to rely on the premise in DSM and ICD that psychopathology of interest is largely categorical rather than dimensional. However, the broader psychopathology literature has expressed growing skepticism about categorical diagnosis. As discussed elsewhere here, NIMH has recently advocated research strategies that do not begin with a categorical premise. Alternatives encourage transdiagnostic and dimensional approaches. Neither of these entails the other-one can conceptualize a symptom categorically without confining it to a single diagnosis. Of course, a hybrid system might work best, not only for qualitatively different psychopathologies but for different regions of the explanatory network. Although the endophenotype concept long predates the NIMH RDoC initiative, one can evaluate how compatible they are.

Some findings for executive function tests and functional brain measures are similar across diagnoses and suggest a common (genetic and/or other) contribution to and common expression of a psychotic dimension. For example, literatures on executive functions as endophenotypes in schizophrenia, bipolar disorders, and to a lesser extent depression show similar results with respect to heritability, disrupted performance in neuropsychological testing, and associated neural systems abnormalities (Ritsner \& Gottesman 2011, Sullivan et al. 2012). Except for verbal fluency, executive function results were similar for patients with schizophrenia or bipolar disorders and their relatives (Juselius et al. 2009) and similar for schizophrenia, bipolar, and obsessive-compulsive disorder patients (Rao et al. 2008). Results are controversial for verbal fluency. Owens et al. (2011) and Wobrock et al. (2009) reported similar deficits in schizophrenia patients and their relatives, whereas Juselius et al. (2009) did not find this similarity in bipolar families for verbal fluency. Evidence of transdiagnostic continuity has also been reported for the inhibitory component of executive function in schizophrenia and bipolar disorder (Besnier et al. 2009, Juselius et al. 2009, Savitz et al. 2008). Ivleva et al. (2012) emphasized considerable similarity of performance deficits in executive functions (including verbal working memory, attention, set shifting, and inhibition) between schizophrenia and bipolar I disorders (see also Bora et al. 2009, Glahn et al. 2010, Savitz et al. 2005, Schulze et al. 2011). In contrast, Jabben et al. (2010) did not find evidence for cognitive deficits as a transdiagnostic endophenotype. Ritsner \& Gottesman (2011) concluded that transdiagnostically overlapping and differentiating endophenotypes and genetic features support a neurodevelopmental origin of schizophrenia, in contrast to bipolar disorders. A review of executive functions in pediatric bipolar and attention deficit-hyperactivity disorders (Walshaw et al. 2010) found similar effect sizes on verbal and spatial working memory tests, suggesting transdiagnostic endophenotypes, whereas substantial differences in tasks assessing inhibitory functions and planning or set shifting suggested disorder-specific endophenotypes. Such patterns of diagnostic convergence and divergence for different executive functions seem quite likely as this literature matures. 
As summarized by Thaker (2008a), P50 gating abnormalities, well established in schizophrenia, are also found in families of bipolar patients. Similarities between schizophrenia and bipolar patients and their first-degree relatives have also been reported for the PPI measure of sensory gating, though less consistently. Such results strengthen the validity of considering sensory gating a transdiagnostic endophenotype. Further consistent with a dimensional view, Cadenhead et al. (2000; see also Ritsner \& Gottesman 2011) reported reduced P50 suppression in individuals with schizotypal personality disorder (abnormalities were not assessed in relatives).

Resting-state brain network connectivity has been examined as another potential endophenotype studied with a transdiagnostic perspective. Such resting-state research (examining interregional correlations over time in fMRI activity patterns at rest) is much newer than most literatures reviewed here, but some relevant methods are particularly amenable to large-sample meta-analyses. For example, Meda et al. (2010, 2012a,b) distinguished abnormal patterns in resting-state networks that are $(a)$ shared between schizophrenia and psychotic bipolar patients and their unaffected relatives or $(b)$ unique to schizophrenia or unique to bipolar patients. Given the growing focus on brain network operation, rather than on an untenable goal of localization of function (Miller 2010, Noë 2009, Uttal 2011), research on functional brain networks offers a more promising basis for endophenotypes.

In sum, available studies suggest that schizophrenia and bipolar disorders represent, at least to an unknown but intriguing degree, a clinical continuum, with overlapping cognitive and functional brain features characterizing a psychosis phenotype (Ritsner \& Gottesman 2011). Sullivan et al. (2012, p. 543) concluded from their review of GWAS that "some of the most intriguing findings for SCZ and BIP are from large sets of genetic markers.... There are now replicated data that vulnerability to SCZ is influenced by common genetic variation in hundreds of different loci, and this vulnerability partially overlaps that for BIP. Indeed, the large-scale impact of large numbers of common variants may be a general feature of human complex traits" (see also Cirulli et al. 2010, Int. Schizophr. Consort. 2009, Moskvina et al. 2009, Owen 2012). Carpenter et al. (2009) went as far as to propose a cluster of psychotic disorders subsuming schizophrenia and bipolar disorders in the proposed meta-structure for DSM-5. Thaker (2008b) emphasized that the overlap of psychophysiological deficits between disorders like schizophrenia and bipolar disorder may not only help the hunt for psychosis liability genes but clarify the extent to which the two major psychotic disorders share etio-pathophysiology.

Such proposals for a continuum of severity in prominent symptoms are inherently dimensional and not very compatible with the tradition of categorical diagnosis. The argument is not just about which approach better suits the clinical phenomena one wants to diagnose but which approach better suits constituent and etiologically prior phenomena. If one moves away from the high priority DSM and ICD have placed on reliable description and attempts to develop a diagnostic system based on theory in hopes of improving validity, one inevitably turns to the dimensional versus categorical nature of the processes that drive the symptoms. Granting, along with most recent authors, that at least many mental disorders reflect the operation of numerous genes and numerous mediating endophenotypes, a purely categorical approach becomes difficult to defend. A typical self-report scale, scored as the sum of individual item scores, is a convenient metaphor. Whether the individual items are conceived as categorical (present/absent) or dimensional (a rating of 1 to $X$ ), on the whole the scale will behave dimensionally. That is, once one assumes a network of contributors, especially when one allows for recursive effects among those contributors, the explanatory system is going to be very difficult to model categorically. A series (perhaps a very large series) of dimensional variables is likely to provide a better fit, although this critique does not preclude the possibility of contributions from categorical phenomena, perhaps via threshold effects. 
Recent endophenotype theorists anticipate multiple endophenotypes for a given traditional disorder, with the role or prominence of at least a subset of the endophenotypes differing by disorder. Thus, complementing transdiagnostic endophenotypes, they also anticipate evidence for disorder-specific endophenotypes. For example, Besnier et al. (2009) reported impaired colorword and emotional Stroop interference in unaffected relatives of schizophrenia patients, whereas only emotional interference was abnormally augmented in unaffected relatives of bipolar patients. Wobrock et al. (2009) reported specific differences between schizophrenia and bipolar patients in Wisconsin Card Sorting Test perseveration but not in verbal learning/memory and verbal fluency tests. Studying resting-state EEG oscillatory activity, Venables et al. (2009) proposed excessive frontal high-frequency activity as a specific endophenotype for schizophrenia because abnormalities were similar in patients and unaffected relatives but not evident in bipolar patients. In contrast, abnormally augmented low-frequency activity was related to schizophrenia-specific pathophysiology, present neither in relatives nor in bipolar patients or their relatives, and was associated with a COMT variant. The findings of Walshaw et al. (2010) for pediatric bipolar and ADHD disorders cited above are another such example. Again, a mix of transdiagnostic and disorder-specific patterns would not be surprising.

Compared to such transdiagnostic evidence, research evaluating the P300 component of the event-related brain potential studied as an endophenotype supports another kind of dimensional perspective. This work mainly concerns substance use disorders (SUDs) and, using comparisons with other disorders like depression, suggests specificity for an externalizing-internalizing dimension. Iacono \& Malone (2011) reviewed persuasive evidence that P300 is heritable and is associated with a range of externalizing disorders (including childhood disruptive disorders and antisocial behavior in addition to SUD; see also Carlson \& Iacono 2008; Euser et al. 2012; Gilmore et al. 2010a,b; Hill 2010; Robbins et al. 2012; Singh \& Basu 2009). They also emphasized a particularly important criterion: the ability to predict later disorder in unaffected individuals, which P300 can do. Prospective studies have shown that reduced P300 present in youth prior to significant exposure to addictive substances is associated with the subsequent development of SUD.

Moreover, GWAS results indicate an overlap between genetic factors contributing to addiction and bipolar disorders (Uhl et al. 2008). Singh \& Basu (2009) even categorized schizophrenia as an externalizing disorder together with SUD, based on P300 evidence. Hill (2010) concluded that P300 qualifies as an endophenotype for SUD as much as for schizophrenia. As noted above, diagnostic specificity is not necessary for an endophenotype both because conventional diagnostic categories are highly problematic (and thus not a good criterion) and because an endophenotype represents just a portion of the etiological path, and such paths can have multiple branches.

Lenzenweger (2010), Reichborn-Kjennerud (2010), and Siever (2005) have suggested that personality traits and/or personality disorders can qualify as endophenotypes for other disorders, as they show substantial heritability (particularly dimensions such as "emotional dysregulation," "dissocial behavior," "inhibition," and "impulsivity") and are associated with Axis I diagnoses. A comparison of symptoms and dimensions of schizotypal personality among schizophrenia patients, unaffected relatives, relatives of patients with affective disorders, and nonpsychiatric controls indicated that social-interpersonal symptoms are much more promising than cognitive and disorganized symptoms as potential endophenotypes (Tarbox \& Pogue-Geile 2011; see also Ritsner \& Gottesman 2011). Gould \& Gottesman (2006) would regard what is widely believed to be the low validity of DSM personality disorder diagnoses as a forbidding obstacle to endophenotype research. If, as is widely believed, the boundaries on DSM personality disorder concepts lack validity, potential endophenotypes could not correlate with them or be meaningfully embodied in them. This problem is not an argument against endophenotype research. On the contrary, it sets the stage for the same argument Gottesman and colleagues have made for the past 
40 years and which the RDoC initiative champions: One should not focus on poorly conceived phenotypes.

The second contention is that endophenotype research supports a transdiagnostic perspective on mental disorder. A number of examples just reviewed support this contention. Studies provided evidence that some established or potential endophenotypes cross traditional diagnostic boundaries and that others do not, although these demonstrations cannot yet be considered definitive. At stake is not whether categorical approaches such as DSM and ICD should be done away with but whether they are a sufficient basis for progress. The growing consensus among psychopathology scholars is that they are not. Whether some other approach will be better instead of, or will add substantially to, such categorical approaches remains to be determined.

\section{Multivariate, Multilevel Approaches Encourage a Change from a Single Causal Chain to a Network Metaphor}

Even from a heavily genetics-oriented perspective on mental illness, epigenetic phenomena alone render a simple explanatory model infeasible (e.g., Radtke et al. 2011, Rutten \& Mill 2009). The need for multilevel, multivariate approaches to integrate large data sets has become more pressing (Kendler \& Neale 2010, Tarbox \& Pogue-Geile 2011). Cannon \& Keller (2006) noted that such approaches should allow for nested levels even within the domain of endophenotypesfor example, those with fewer, simpler genetic (and other) determinants combining to create downstream endophenotypes.

Recent examples of ambitious, promising approaches testing novel multivariate methods are appearing (e.g., Gilmore et al. 2010b; Glahn et al. 2010, 2012; Sabb et al. 2009). Several reviews have undertaken to integrate evidence within a domain, either neural systems or genetic factors, providing recommendations for multilevel integration. Next, studies have begun to integrate evidence across these domains, such as brain (MRI) and genetic (GWAS) data ("imaging genetics" per De Geus 2010, De Geus \& Boomsma 2001, Goldman 2012, Meyer-Lindenberg 2010). For example, Karlsgodt et al. (2010) examined the relationship between brain connectivity measures, structural MRI, and working memory performance using 467 probands from extended families as a basis for genetic similarity. Only performance on a spatial delayed response task and integrity of frontoparietal connection shared genetic bases. MacDonald et al. (2009) concluded in their review of fMRI results addressing four domains of cognition in unaffected first-degree relatives of schizophrenia patients that "no single region or mechanism of abnormalities has yet emerged" (p. 1142). For DISC1 polymorphisms, Carless et al. (2011) determined associations with 188 quantitative brain measures, some of them associated with executive, memory, or other aspects of cognition and also correlations with clinical variables (depression, panic), in 1,232 pedigreed probands. DISC1 sequence varied with working memory performance and with cortical gray matter thickness in parietal, temporal, and frontal lobes, whereas different polymorphisms were related to clinical variables.

These findings show correlations (not causal relations) between just pairs of domains. A next step is multivariate, multilevel approaches. Sabb et al. (2009, p. 88) judged them promising for representing relationships between numerous intermediate phenotypes and "to identify the complex unfolding of biological paths from genome to syndrome." (Of course, there is no reason to limit such an approach to biological measures.) They suggested that GWAS, neuroscience, and endophenotype research all suffer from the limitations of $(a)$ ill-defined phenotypes that "often reflect a combination of folk psychology and popular buzz-words," (b) insufficiently or inadequately considering latent constructs that "had been reframed without equal advances in paradigm development," $(c)$ ill-defined phenotype relationships between all levels of inquiry, including neural 
systems and signaling pathways, and $(d)$ GWAS results validating medical disorders (e.g., type I diabetes) more than mental disorders. As an alternative to considering specific endophenotypes as a link in a more or less causal chain between genes and behavior, Sabb et al. (2009, p. 91) made a recommendation "to draw the entire map, but not tell the field how to get from point $\mathrm{A}$ to point B" and cited http://www.phenowiki.org as a novel resource for the field. Sabb et al. (2009) provided an example of a multivariate, multilevel approach, creating a "map" for memory (in a healthy population) including performance evidence as a latent endophenotype, neural systems [such as prefrontal cortex (PFC), hippocampus, and temporal lobe], molecular mechanisms, and relationships to dysfunction such as schizophrenia. Correlations between levels indicated that several proposed genetic associations are speculative at best. As mentioned above, only a small portion of construct variance (memory) was explained by genetic contribution (about 7\%), although putative heritability of some $50 \%$ is assumed.

Appropriate samples and rich analytic strategies are rare but becoming more common. Using multivariate analyses, Gilmore et al. (2010b) demonstrated diverse EEG characteristics having both shared and divergent relationships to externalizing disorders. Glahn et al. (2012) presented a new method for identifying endophenotypes (for initial commentary, see Gotlib \& Hamilton 2012; for another ambitious and impressive strategy, see Greenwood et al. 2012). They proposed an endophenotype ranking value (ERV) as an index on which high scores result from a combination of $(a)$ heritability of the disorder, $(b)$ heritability of the putative endophenotype, and $(c)$ correlation between the disorder and the phenotype. Although quite impressive in initial results, the design of this index highlights some of the challenges of endophenotype research. The third contributor to the index will tend to favor endophenotypes that are phenomenologically and perhaps etiologically close to the conventional disorder. Less directly, the second contributor will favor endophenotypes with a relatively simple genetic input. For example, genetically driven phenomena that arise substantially from epigenetic factors or emergenesis (Lykken et al. 1992), a coincidence of individually very rare and uncorrelated genetic factors, would tend to score poorly on the ERV. This is not a criticism of the ERV, just a note on a limitation on what it can achieve.

Glahn et al. (2012) also applied these methods to endophenotypes for recurrent major depression. A set of more than 11,000 measures from various domains (behavioral, cognitive, neuroanatomic, and quantitative genetic) was obtained from 1,122 individuals. This set was statistically reduced to rank-ordered associations between phenotype and disorder considering shared genetic factors. Top-ranking associations defined a pattern characterized by a symptom measure (Beck Depression Inventory), a neuroanatomic measure (bilateral ventral diencephalon volume), and a genetic measure (expression of the RNF123 transcript). Thus, the defined endophenotypes reflected a pattern of associated measures from several domains.

Meda et al. (2010) applied multivariate, parallel independent component analysis to fMRI data from an auditory oddball task and genetic polymorphisms that both have been associated with schizophrenia. Independent component analysis identified three fMRI components that correlated with distinct gene components. The identified brain regions (PFC, ACC, superior temporal gyrus, and middle temporal gyrus) and gene components (BDNF, DAT, 5HT'TLPR) were known individually to be associated with schizophrenia pathology, but the three patterns of specific associations that emerged (PFC-ACC with BDNF and DAT, superior temporal gyrus-middle temporal gyrus with 5HTTLPR, and default-mode network with BDNF and DAT) were novel. The same group employed this ambitious strategy with a neurological disorder. Meda et al. (2012b, Bullmore 2012) compared associations of 94 brain regions derived from structural MRI scans and GWAS data (533,872 single nucleotide polymorphisms) in a 757-subject, 50-site study of Alzheimer's disease. The analysis identified four distinct genetic components (each including genes known to contribute to disorder risk or pathology) and their link to a structural brain network (including 
regions involved in the pathology). Meda et al. (2012a) used a similar strategy to study schizophrenia, bipolar disorder, and first-degree relatives.

These ambitious, impressive approaches are beyond the reach of most investigators working in isolation. Large-scale data aggregation, in principle, can provide access to such a database to the larger community. For example, Bertram (2008) described a database of genetic association studies in schizophrenia, with more than 1,700 studies available as of fall 2012. If the likely solution space involves numerous variables in multiple relationships with each other, many of which are directly or indirectly reciprocal, and most (or all) making but a small contribution, it is difficult to imagine that anything less will suffice. On the other hand, the sample sizes required in some cases can make the testing burden enormous (for example, to deal with the multiple comparison problem and with small individual effect sizes). That problem has led to the prediction that sufficiently powered but atheoretical GWAS studies of $\mathrm{GxE}$ phenomena will prove to be infeasible (Chabris et al. 2012, Vrieze et al. 2012a), perhaps requiring 50,000 to 100,000 cases (Owen 2012), although bootstrapping methods and other techniques may provide some antidote for some purposes (e.g., Greenwood et al. 2012, Lubke et al. 2012).

Furthermore, multivariate contexts are not immune to standard psychometric challenges. Issues of differential deficit, measure reliability, and item discriminability (Miller et al. 1995) are rarely discussed. Kendler \& Neale (2010) discussed the need to deal with measurement error explicitly, not only because error is problematic but also because it is often quite uneven across measures. Miller \& Chapman (2001) and Zinbarg et al. (2010) considered problems of measurement more extensively, with emphasis on analysis contexts in which predictor variables share considerable variance. The promise of these demanding approaches will no doubt be realized slowly, as the field learns how to foster and improve them.

It should be noted that such "big data" approaches, while surely necessary, are not the only valuable strategy. Using the Golden \& Meehl (1979) strategy of combining individually rare, uncorrelated indicators, discussed above, Iacono et al. (2000) demonstrated that two endophenotypes in combination were associated with much higher risk for SUDs than was either endophenotype alone.

The third contention is that multivariate, multilevel approaches encourage a change from a single causal chain to a network of data and constructs with well-specified relationships. An undeveloped network metaphor is not an account of how endophenotypes mediate between other phenomena. It does, however, respect the growing consensus that, at least in many cases, genetic and other contributions to psychopathology do not individually contribute much of the variance and that there is a web of relationships that needs to be understood.

\section{SIX CHALLENGES}

\section{Challenge 1: A Network Model of Explanation Must Replace a Serial Model}

A very fundamental challenge for endophenotype research arises from the combination of three assessments of the respective roles of genes and environment in psychopathology. First, Kendler (2005a) and others have argued that in mental illness the action will be in the GxE interactions and correlations, not in the main effect of genes. Second, however, Turkheimer (2000) made a compelling case that much of the environmental variance that matters in psychopathology (including in $\mathrm{GxE}$ ) is unshared, that is, idiosyncratic to an individual life, and thus extraordinarily difficult to measure. Third, even if there are cases where predominantly genetic variance drives psychopathology, the multigene combination may be so rare as to be virtually undetectable (Lubke et al. 2012, Lykken et al. 1992, Owen 2012). In light of these assessments, prospects for 
nailing down solid $\mathrm{G}$ or $\mathrm{GxE}$ stories in psychopathology seem quite bleak. But there may be $\mathrm{G}$ or $\mathrm{GxE}$ signals among all the noise, where clear relationships can be found. The concept of endophenotype and its implementation in $\mathrm{RDoC}$, discussed below, are designed to find them. Thus, these difficulties only increase the need for endophenotype research.

In contrast to the original hope of finding single major genes as much of the story for at least some DSM/ICD categories, it has become clear that the appealingly simple serial model of causation represented in genes $\rightarrow$ (other) biology $\rightarrow$ psychology $=$ diathesis and diathesis + environment $\rightarrow$ psychopathology is nowhere near sufficient. Yet it seems not widely understood that genes, other biological phenomena, psychological phenomena, and environmental phenomena can intervene at essentially all points in the etiological chain (Cannon \& Keller 2006).

Genes likely intervene throughout etiology, and so do the other factors-other biological, psychological, and environmental contributors. As a result, endophenotype research can help us discover more than gene inputs. We are going to need a lot more arrows in our models, we are going to have to let go of the serial causation model, and we are going to have to stop confining genes to the entry points of the models we do use. Endophenotype research has twin goals of identifying the genetic contributions to psychopathology and identifying the mechanisms by which those contributions contribute. Genes are not the beginning of the causal chain. There is no chain, and there is no beginning. The first challenge is a repositioning of genes in our explanatory space and understanding the elements in that space as a network of observations, constructs, and bridge principles relating them (Kozak \& Miller 1982) via a theory-building bootstrapping process (Patrick et al. 2012).

\section{Challenge 2: Better-Developed Notions of Cause and Mechanism Are Needed}

The second goal, identifying the mechanisms by which endophenotypes contribute, faces an especially difficult challenge. Unfortunately, the notions of "cause" and "mechanism" are not themselves fully fleshed out or consensually shared (Miller 2010). This is difficult enough when we try to characterize mechanisms within what might be called a single level or domain of analysis. For example, neural currents underlie the scalp EEG and magnetoencephalography (MEG) signals we can record noninvasively, but it can be quite challenging to model the sources of those signals with high confidence. Spatial localization with EEG and MEG at its best equals that of routine fMRI (Aine et al. 2012, Miller et al. 2007), but many research questions would benefit from doing much better. Still, there is no logical barrier to progress in such modeling, as we believe we do know how neural signals produce scalp signals.

Identifying mechanisms when we try to cross levels or domains of analysis is much more difficult. In an earlier article in the Annual Review of Clinical Psychology, Kazdin (2007, p. 3) offered perfectly reasonable definitions: "Cause: a variable or intervention that leads to and is responsible for the outcome or change.... Mechanism: the basis for the effect, i.e., the processes or events that are responsible for the change; the reasons why change occurred or how change came about." Cannon (2009) emphasized a series of transductions, each (somehow) crossing levels of analysis in a causal model, combining to create a causal cascade. Contributors at a given stage may or may not continue to contribute later in the cascade. If one allows feedback in such a model, one ends up with a rich causal network.

One can understand endophenotypes as subject to the same GxE factors as is commonly assumed for clinical disorders. In fact, to look for one or a few endophenotypes whose operation could be understood in isolation and would be expected to make a substantial contribution to mental illness would merely replicate the misplaced hope of several decades ago, when the aim was to find single major gene effects. We will be lucky to find single major endophenotype effects. 
Even if one were found, even if it were shown to be part of the specific etiology of a disorder, it would not necessarily provide a feasible locus of intervention. We would need to decipher the rest of the explanatory path and to explore points of leverage on that path.

We are not going to be able to lay out a rich explanatory network for psychopathology that includes genes and other biological phenomena until we conceive and identify mechanisms that can cross between explanatory domains, processes by which events at one level cause events at another level. As elaborated by Miller (2010; see also Noë 2009), an example of a mechanistic account of how specific biological events cause specific psychological events has yet to appear in the neuroscience literature, let alone in the psychopathology literature (e.g., Crick \& Koch 2003, p. 119: "No one has produced any plausible explanation as to how the experience of the redness of red could arise from the actions of the brain"). The "patchy reductionism" advocated by Kendler (2005b), in line with the analysis of reductionism by Lilienfeld (2007), the developmental systems perspective of Goldhaber (2012), and the construct-network proposal of Patrick et al. (2012), may be a fruitful way to approach this task.

\section{Challenge 3: The Clinical Phenomena of Interest Are Psychological}

The premise that the defining phenomena of mental illness are psychological is a challenge to the 40 years of pursuit of endophenotypes too often premised on an essentialist and naively reductionist view of the role of brain abnormalities in mental disorder and in fact a challenge to the bulk of research on psychopathology in that period. The problem is trivially apparent in the recently common, vacuous relabeling of many cognitive tasks as "neurocognitive." On the contrary, as argued above, the fundamental phenomena of mental illness are psychological. This was the view of Meehl (1972, pp. 396-397), an early champion of genes mattering in psychopathology, writing in the Afterword of the Gottesman \& Shields book: “... I cannot conceive...that [schizotypy] is inherited. Being [schizotypal] is having certain kinds of behavior and mental life...; none of this could possibly be 'in the genes'.... If (as I believe Professor Gottesman has agreed in conversation with me) delusions and hallucinations and catatonic posturing cannot possibly be transmitted by the genes...." Similarly, Kendler (2005a, p. 433) stated: "Psychiatry is irrevocably grounded in mental, first-person experiences." Tan et al. (2008, p. 233) agreed: "Genes do not encode for psychopathology; nor for hallucinations, delusions, thought disorganization; panic attacks or sadness. To the extent that genes are associated with such characteristics, for example the symptom constellation that we call schizophrenia, they do so by affecting the development and function of brain cells and neural systems that mediate the expression of such behavioral and perceptual phenomena." Schizophrenia is a constellation of symptoms (not a brain disease), and those symptoms are psychological, not biological. But unfortunately that understanding has not been the center of gravity in what we have called the recent Decades of the Brain (Miller 2010).

On the assumption that it is fairest to pick on some of the most respected names in the field, we note that problematic statements such as the following have become routine: "The endophenotype strategy offers powerful and exciting opportunities to understand the genetically conferred neurobiological vulnerabilities and possible new strong inference and molecularly based treatments for schizophrenia" (Braff et al. 2007, p. 21). This was a summary statement in a paper not limited to the biology of schizophrenia, but rather addressing the use of endophenotypes to understand schizophrenia (all of schizophrenia, not just the biology of schizophrenia). It was a valid statement, but it left out vulnerabilities not conceived biologically and treatments not driven by molecular genetics research. It reflects a reductionist view that psychopathology should be understood as a "complex genetic psychiatric disorder" (Braff et al. 2007, p. 22) or "real, diagnosable, treatable brain disorders" (Hyman 1998, p. 38). But such a view is untenable: "The 
idea that the only genuinely scientific study of [mental events such as] consciousness would be one that identifies consciousness with events in the nervous system is a bit of outdated reductionism. It is comparable to the idea that depression is a brain disease" (Noë 2009, p. xii).

The pervasiveness of the naively reductionist construal of what are definitionally psychological disorders, not brain disorders, has been documented and the policy dangers it fosters discussed (Miller 2010). The unfortunate premises promoted by such statements are that, when we tackle the genetics of mental illness, (a) we are focusing on the biology, not the full story, and $(b)$ that narrow focus will suffice. An individual research program must have a narrow focus, pursuing only parts of the story, but the research agenda for the field as a whole must remain broad.

As the review above of the evolution and clarification of the concept of endophenotypes made clear, endophenotypes should not be conceived as necessarily biological phenomena in any direct sense. Thus, endophenotype research is at the forefront of the pendulum swing away from the excesses of the Decades of the Brain, toward a biologically informed but not constrained agenda exemplified in the RDoC initiative. Endophenotype research is now positioned to illuminate not only the genetic contributions to psychopathology but also other contributions. The third challenge is to let go of naïve reductionism and to pursue endophenotype research, appreciating the full breadth of its potential contribution.

\section{Challenge 4: Primary Reliance on DSM and ICD Categorical Approaches Must Stop}

An increasingly common judgment is that reliance on conventional psychiatric diagnosis and categorical diagnostic concepts greatly undermines psychopathology research (e.g., Angst 2007, Hyman 2010, Jablensky 2010, Ritsner \& Gottesman 2011). Studies rely on DSM or ICD diagnoses, which may introduce a systematic bias, because these diagnostic systems have (now for decades) deferred diagnostic validity in favor of prioritizing reliability and shared language.

A popular example is that there is no research justification or validation for having a threshold of five out of nine symptoms defining major depressive disorder (Hyman 2010). Similarly, cognitive dysfunction is not a diagnostic criterion for schizophrenia, though arguably it is one of the most disruptive features of and one of the best classes of candidates for endophenotypes (Cirulli et al. 2010). About the validity problem in DSM, Insel (2012) commented: "What is missing is validity. DSM never presumed to confer validity or explanatory value, but the field has imbued these symptom clusters with biological meaning, perhaps understandable in the absence of biomarkers or diagnostic tests. Ironically, this linguistic oversight has precluded the development of biomarkers that might confer validity." As a result, potential endophenotypes are routinely judged against diagnostic criteria of questionable validity. Reliance on DSM or ICD may also obscure partly shared genetic risk factors, such as understanding the relationship between anxiety and depression.

\section{Challenge 5: Endophenotype Research Needs Broad Collaborations}

Unknown and probably underappreciated is how far we can get with shared environment assessed at very low granularity. Characteristics affected by genes do not have heritability in some general sense. A given estimate of heritability is defined only in a particular population in a particular environment (Johnson et al. 2009). For example, the heritability of IQ depends on socioeconomic status, with more poverty associated with lower heritability (Turkheimer et al. 2003). Can we consider urbanicity (living in an urban environment) a potential endophenotype for psychosis? van Os et al. (2010) reported that urbanicity raised the risk for psychotic diagnoses only in the presence of genetic liability. In social stress experiments, Lederbogen et al. (2011) demonstrated distinct impacts of distinct environmental factors such as current city living versus past urban upbringing on 
functional brain measures that have been proposed as endophenotypes. As noted previously, Laland et al. (2010) argued that human culture has had a substantial role in selection pressures affecting hundreds of genes. Such findings speak to the criterion of the biological validity of endophenotypes, including endophenotypes that are not themselves directly biological. Endophenotype researchers pursuing psychopathology should collaborate with psychiatric epidemiologists, sociologists, and anthropologists as well as geneticists and neuroscientists.

\section{Challenge 6: Statistical Search in Genetic Databases Should Be Informed by Psychophysiological Research}

Progress is needed in using advances in central nervous system psychophysiology including functional neuroimaging (EEG, MEG, and optical measures of neural function; magnetic, radiological, and optical measures of hemodynamics) to inform and constrain newly developing statistical search methods in genetic and multilevel databases, as a means to guide and constrain potentially enormous solution spaces. Such progress will depend in part on training a higher proportion of investigators in advanced methods in both areas and in fostering collaborations among experts in each.

\section{MUTUAL IMPLICATIONS OF ENDOPHENOTYPES AND RDOC}

The endophenotype movement has achieved a great deal and will achieve much more. It has led the field to think more carefully and more critically about what the relationships can be between nature and nurture, and it has fed the first fundamental redesign of NIMH strategy since the pendulum began its swing from radical behaviorism to naïve biological reductionism and radical pharmacism. The new NIMH strategic plan now calls for "new ways of classifying mental disorders based on dimensions of observable behavior and neurobiological measures" (Insel \& Cuthbert 2009, p. 989). Although carefully couched as being fully in the tradition that led to the modern DSM ("The RDoC project is intended to be the next step in a long journey, one that continues the process begun in the 1970s..."; Insel et al. 2010, p. 748), it brings a radical change to psychopathology research and perhaps eventually to clinical practice.

"The primary focus for RDoC is on neural circuitry, with levels of analysis progressing in one of two directions: upwards from measures of circuitry function to clinically relevant variation, or downwards to the genetic and molecular/cellular factors that ultimately influence such function" (Insel et al. 2010, p. 749). This characterization is remarkably reminiscent of Gottesman and others discussing endophenotypes. In fact, $\mathrm{RDoC}$ brings the realm of endophenotypes to the foreground of the research enterprise. "For cognitive processes, as with other areas of research on mental disorders, burgeoning knowledge about fundamental programs of behavior, and their implementing neurobiological circuitry, mandates a shift in thinking about the classification of psychiatric disorders" (Morris \& Cuthbert 2012, p. 29). Surely not every intermediate phenomenon of interest to the RDoC initiative will qualify as an endophenotype. But potentially every endophenotype can contribute to RDoC efforts.

The emphasis in the RDoC initiative on dimensional measures is prominent. "The RDoC matrix [takes] a dimensional approach to the study of the genetic, neural, and behavioral features of mental disorders" (Morris \& Cuthbert 2012, p. 29). In fact, RDoC was designed unabashedly to "encourage scientists to break free of categorical diagnostic constraints..." (p. 30). This value judgment aligns very well with the endophenotype literature. As a matter of definition, endophenotypes are not confined to continuously variable phenomena, and combinations of phenomena that each vary continuously may show threshold effects. But many scholars writing about endophenotypes have favored dimensional measures of such phenomena. For example, 
Cannon \& Keller (2006) and Iacono \& Lykken (1979) suggested that endophenotypes should vary continuously in the general population (see Gottesman 1963 for a foreshadowing of such dimensional endophenotypes). Kendler \& Neale (2010, p. 796) noted that endophenotypes "are typically quantitative, thereby providing more information than the dichotomous diagnostic assessment used for psychiatric disorders." Gregoire et al. (2012, p. 202) argued that "The synergy of working memory and inhibitory abilities, observed in both healthy and psychiatric populations, may originate from endogenous variability in dopaminergic prefrontal cortex activity. Such findings confirm the validity of a dimensional approach, based on the concept of continuity between health and mental disorders for identifying endophenotypes of mental disorders."

A transdiagnostic, dimensional approach is quite compatible with the strategy common in endophenotype research that compares patients, unaffected relatives, and healthy individuals, framing a progression to greater symptom severity (e.g., healthy $\rightarrow$ personality traits $\rightarrow$ personality disorders $\rightarrow$ depression $\rightarrow$ functional psychosis; Frances \& Widiger 2012, Ritsner \& Gottesman 2011, Skodol 2012, Widiger 2011, Widiger \& Mullins-Sweat 2009). Vrieze et al. (2012a) emphasized the need for better measurement of environments and cited several grounds for favoring dimensional measures more broadly:

While a categorical measurement of disease status may effectively facilitate the pooling of resources, it may not be an optimal way to measure disease and/or a trait. It is well-known that binary diagnoses throw away an immense amount of information, and have lower statistical power compared even to rough quasi-continuous measures of the same constructs, like symptom counts (Markon et al. 2011). It is rarely true in psychology that a binary classification is better for statistical analysis than a quasicontinuous one (Grove 1991), but arguments favoring of the use of quantitative indicators is not based on statistical power alone. Some of the phenotypic measurements of interest to psychopathologists appear to be better represented by continuous dimensions of variation rather than as discrete entities (Krueger et al. 2005; Vrieze et al. 2012; although see Vrieze 2012), a conclusion that has moreover been consistently supported in behavioral genetic research.

Another fundamental characteristic that the recent endophenotype literature and the RDoC initiative share is placing a high value on contributions from animal neuroscience (Conklin \& Iacono 2002, De Geus \& Boomsma 2001, Gottesman \& Gould 2003, Gould \& Gottesman 2006, Hunsaker 2012, Oliver 2011, Walters \& Owen 2007). In fact, one of the principal ways in which endophenotypes are valuable in genetically sensitive neuroscience research is that they provide analogous phenotypic correspondences between humans and animal models. For example, in animals relevant genes can be manipulated and the resulting brain structure, function, physiology, and behavior studied (e.g., Braff 2010, Goldman 2012, Hunsaker 2012, Lutkenhoff et al. 2012, Takahashi et al. 2011). Kaffman \& Krystal (2012, pp. 3 and 16) argued that

...such translational work should focus on the role that genes and/or environmental factors play in the development of circuits that regulate specific physiological and behavioral outcomes in adulthood. This emphasis on circuit development, as a fundamental unit for understanding behavior, is distinct from current approaches of modeling psychiatric illnesses in animals in two important ways. First, it proposes to replace the diagnostic and statistical manual of mental disorders (DSM) diagnostic system with measurable endophenotypes as the basis for modeling human psychopathology in animals. We argue that a major difficulty in establishing valid animal models lies in their reliance on the DSM/International Classification of Diseases conceptual framework, and suggest that the Research Domain Criteria project, recently proposed by the NIMH, provides a more suitable system to model human psychopathology in animals. 
Second, this proposal emphasizes the developmental origin of many (though clearly not all) psychiatric illnesses, an issue that is often glossed over in current animal models of mental illness. We suggest that animal models are essential to elucidate the mechanisms by which neuro-developmental changes program complex behavior in adulthood ... The DSM/ICD system may be useful for describing clinical impairment but not for uncovering psychopathology or guiding treatment. The RDoC initiative should facilitate the identification of endophenotypes that are likely to be more informative regarding the pathophysiology and intervention strategies. Such endophenotypes would also improve construct validity of animal models in psychiatric research by providing important postmarks to guide this work....

The endophenotype literature is not constrained by one unfortunate limitation of the RDoC initiative. The first of three "postulates" of the RDoC framework is that "mental illnesses are presumed to be disorders of brain circuits" (Morris \& Cuthbert 2012, p. 33). As noted above and argued elsewhere (Miller 1996, 2010), this is not presently a viable stance, and it appears unlikely ever to be. Psychopathology is, as a matter of definition, psychological, and psychological constructs are not reducible to biological constructs. The endophenotype literature has grown well beyond its initial temptation to reduce the key processes of psychopathology to genetics. It is now increasingly understood that, at least until mechanisms that cross domains of phenomena are identified, no domain is more fundamental than another.

The endophenotype concept and the RDoC effort are natural allies. RDoC is causing considerable tension in the field, but the main objection appears to be pragmatic: It will be very, very difficult to change how clinicians conceive of psychopathology. But inertia is not a compelling defense of the status quo, with which few clinicians and clinical scholars are happy. It is also very difficult to argue against the grounding of RDoC in state-of-the-art animal neuroscience and in research on fundamental dimensions of biological and psychological phenomena, pursued without naïve reductionism.

\section{CONCLUSIONS}

The endophenotype enterprise has been a success in finding intermediaries among factors contributing to psychopathology. The concept has also evolved in response to extensive research efforts. The very efforts that have supported the wager that genes matter greatly have also demonstrated that environments matter greatly. Some 20,000 protein-forming genes alone appear to be only a small portion of the story in psychopathology, and recent work points to a role for thousands more regulatory factors comprising additional portions of the genome. There are now simultaneous and entirely compatible pushes in the endophenotype literature for better grounding in biological phenomena, including genes and epigenomics (heritable changes in gene expression not simply due to DNA), and for a broader net regarding what can count as an endophenotype.

If endophenotypes need not be directly biological phenomena (even though biologically validated in some way) and need not be specific to a given DSM/ICD categorical diagnosis, why retain the concept? Let us grant that there are measureable phenomena, not themselves considered to be psychopathology or symptoms of it but related to it in ways that reflect genetic contributions, that may prove valuable in understanding the etiology of mental illness and identifying intervention targets and methods. It would be useful for the field to have a well-developed, consensual conceptualization of such phenomena and to have an articulated set of criteria for evaluating proposed roles for such phenomena. For example, heritability and correlation with illness would be appealing characteristics of such phenomena. In short, if we did not have the concept of endophenotype, 
we would benefit from inventing it-from articulating what we are looking for to bridge genes, environment, and mental illness.

The yield to date from the endophenotype literature is nevertheless much less than hoped, because the etiological mechanisms appear to be much more complex than envisioned and because the diagnostic terrain appears not to have been well mapped by historically dominant categorical diagnostic systems. Other challenges were noted above. Thus, 40 years' pursuit of the endophenotype concept has led to some humility about the challenge of discovering the explanatory network involved in psychopathology. The present review finds much more success in endophenotype identification than in finding the genes involved or the mechanisms by which genes and environments combine to foster or limit psychopathology. Concerted efforts are now underway to place psychologically sophisticated animal and human neuroscience at the center of the research enterprise-not genes, and not traditional clinical presentation, though both will remain essential to discovering the full story of psychopathology and advancing its prevention, assessment, and amelioration.

We suggest that the endophenotype enterprise has disappointed not because of shortcomings of the concept but rather because of the premise that endophenotypes need to point to existing DSM/ICD categorical disorders and to naively simple assumptions about the role of genes in psychopathology. The effort to link genes (and environments and GxE interactions and geneenvironment correlations) to endophenotypes can continue as the field (via RDoC and other venues) improves its diagnostic conceptualizations. Surely a more successful diagnostic system will accommodate both categorical and dimensional views of various phenomena, but in any case endophenotype research should be freed of the burden of conventional diagnostic categories as the explanatory goal.

Four short-term recommendations can be offered. First, we do not need more studies reporting that $X$ may be an endophenotype for $Y$. At this point there is very little information value in such statements. Second, simply testing some of those $X$ 's against systematic criteria for qualifying as an endophenotype, though much more useful, warrants less priority than fleshing out the mechanisms of those in hand. Preferably, proposed mechanisms collectively will explicate a web of relationships, not a simple causal chain. Third, because some of the most promising methods of exploring causal networks are extremely demanding, and in fact beyond the capacity of most laboratories, there is a need to develop shared or readily shareable research resources for pooling data and developing and propagating analysis methods. For example, collaborative, multivariate, multilevel projects could be a priority for the RDoC initiative (e.g., Calkins et al. 2007). Finally, although cross-disciplinary collaboration among those with distinct expertise is essential, cross-disciplinary training of individuals is even more important. This is another area where NIMH/RDoC could fruitfully make some extra investments.

The endophenotype approach was translational before "translational" became a pervasive buzzword. ("...the [RDoC] scheme is inherently translational"; Cuthbert \& Insel 2010a, p. 312). The $\mathrm{RDoC}$ initiative is arguably a full embrace of the endophenotype tradition, looking for psychological and biological mechanisms in any domain that provide comprehension of and leverage against psychopathology. The field has finally come around to what Gottesman \& Shields (1972) proposed. Endophenotype research will only grow in centrality.

\section{DISCLOSURE STATEMENT}

The authors are not aware of any affiliations, memberships, funding, or financial holdings that might be perceived as affecting the objectivity of this review. 


\section{ACKNOWLEDGMENTS}

The authors thank Howard Berenbaum, Tyrone D. Cannon, Danielle M. Dick, Irving I. Gottesman, William G. Iacono, Kenneth S. Kendler, Daniel N. Klein, Michael J. Kozak, Christopher J. Patrick, Robert F. Simons, and Cindy M. Yee-Bradbury for consultation as well as the Deutsche Forschungsgemeinschaft, the Zukunftskolleg of the University of Konstanz, and NIMH grant P50 MH079485 for financial support.

\section{LITERATURE CITED}

Aine CJ, Sanfratello L, Ranken D, Best E, MacArthur JA, et al. 2012. MEG-SIM: a Web portal for testing MEG analysis methods using realistic simulated and empirical data. Neuroinformatics 10:141-58

Am. Psychiatr. Assoc. 2000. Diagnostic and Statistical Manual of Mental Disorders. Washington, DC: Am. Psychiatr. Assoc. 4th ed., text rev.

Ancin I, Cabranese JA, Vazquez-Alvarez B, Santos JL, Sanchez-Moria E, et al. 2011. Sensory gating deficit is associated with catechol-O-methyltransferase polymorphism in bipolar disorder. World 7. Biol. Psychiatry 12:376-84

Angst J. 2007. Psychiatric diagnoses: the weak component of modern research. World Psychiatry 6:94-95

Archer T, Oscar-Berman M, Blum K. 2011. Epigenetics in developmental disorder: ADHD and endophenotypes. 7. Genet. Syndr. Gene Ther. 2:104-37

Bearden CE, Karlsgodt KH, Bachman P, van Erp TGM, Winkler AM, Glahn DC. 2012. Genetic architecture of declarative memory: implications for complex illnesses. Neuroscientist 18:516-32

Bertram L. 2008. Genetic research in schizophrenia: new tools and future perspectives. Schizophr. Bull. 34:80612

Besnier N, Richard F, Zendjidjian X, Kaladjian A, Mazzola-Pomietto P, et al. 2009. Stroop and emotional Stroop interference in unaffected relatives of patients with schizophrenia and bipolar disorders: distinct markers of vulnerability. World 7. Biol. Psychiatry 19:809-18

Bora E, Yucel M, Pantelis C. 2009. Cognitive endophenotypes of bipolar disorder: a meta-analysis of neuropsychological deficits in euthymic patients and their first-degree relatives. F. Affect. Disord. 113:1-20

Braff DL. 2010. Prepulse inhibition of the startle reflex: a window on the brain in schizophrenia. Curr. Top. Bebav. Neurosci. 4:349-71

Braff DL, Freedman R, Schork NJ, Gottesman II. 2007. Deconstructing schizophrenia: an overview of the use of endophenotypes in order to understand a complex disorder. Schizopbr. Bull. 33:21-32

Bullmore E. 2012. Functional network endophenotypes of psychotic disorders. Biol. Psychiatry 71:844-45

Cadenhead KS, Light GA, Geyer MA, BraffDL. 2000. Sensory gating deficits assessed by the P 50 event-related potential in subjects with schizotypal personality disorder. Am. 7. Psychiatry 157:55-59

Calkins ME, Dobie DJ, Cadenhead KS, Olincy A, Freedman R, et al. 2007. The Consortium on the Genetics of Endophenotypes in Schizophrenia: model recruitment, assessment, and endophenotyping methods for a multisite collaboration. Schizophr. Bull. 33:33-48

Calkins ME, Iacono WG, Ones DS. 2008. Eye movement dysfunction in first-degree relatives of patients with schizophrenia: a meta-analytic evaluation of candidate endophenotypes. Brain Cogn. 68:436-61

Cannon TD. 2005. The inheritance of intermediate phenotypes for schizophrenia. Curr. Opin. Psychiatry 18:135-40

Cannon TD. 2009. What is the role of theories in the study of schizophrenia? Scbizophr. Bull. 35:563-67

Cannon TD, Keller MC. 2006. Endophenotypes in the genetic analyses of mental disorders. Annu. Rev. Clin. Psychol. 2:267-90

Carless MA, Glahn DC, Johnson MP, Curran JE, Bozaoglu K, et al. 2011. Impact of DISC1 variation on neuroanatomical and neurocognitive phenotypes. Mol. Psychiatry 16:1096-104

Carlson SR, Iacono WG. 2008. Deviant P300 amplitude development in males is associated with paternal externalizing psychopathology. F. Abnorm. Psychol. 117:910-23

Carpenter WT, Bustillo JR, Thaker GK, van Os J, Krueger RF, Green MJ. 2009. The psychoses: cluster 3 of the proposed meta-structure for DSM-V and ICD-11. Psychol. Med. 39:2025-42 
Chabris CF, Hebert BM, Benjamin DJ, Beauchamp J, Cesarini D, et al. 2012. Most reported genetic associations with general intelligence are probably false positives. Psycbol. Sci. 23:1314-23

Chan RC, Gottesman II. 2008. Neurological soft signs as candidate endophenotypes for schizophrenia: a shooting star or a Northern star? Neurosci. Biobebav. Rev. 32:957-71

Chen Y-H, Edgar JC, Huang M, Hunter MA, Epstein E, et al. 2012. Frontal and superior temporal auditory processing abnormalities in schizophrenia. Manuscript under review

Cirulli ET, Kasperaviciute D, Attix DK, Need AC, Ge D, et al. 2010. Common genetic variation and performance on standardized cognitive tests. Eur. F. Hum. Genet. 18:815-20

Conklin HM, Iacono WG. 2002. Schizophrenia: a neurodevelopmental perspective. Curr. Dir. Psychol. Sci. 11:33-37

Courtet P, Gottesman II, Joliant F, Gould TD. 2011. The neuroscience of suicidal behaviors: What can we expect from endophenotype strategies? Transl. Psychiatry 1:e7

Crick F, Koch C. 2003. A framework for consciousness. Nat. Neurosci. 6:119-26

Cuthbert BN. 2005. Dimensional models of psychopathology: research agenda and clinical utility. 7. Abnorm. Psychol. 114:565-69

Cuthbert BN, Insel TR. 2010a. The data of diagnosis: new approaches to psychiatric classification. Psychiatry 73:311-14

Cuthbert BN, Insel TR. 2010b. Toward new approaches to psychotic disorders: the NIMH Research Domain Criteria project. Schizophr. Bull. 36:1061-62

De Geus EJC. 2010. From genotype to EEG endophenotype: a route for post-genomic understanding of complex psychiatric disease. Genome Med. 2:63

De Geus EJC, Boomsma DI. 2001. A genetic neuroscience approach to human cognition. Eur. Psychol. 6:24153

Dick DM. 2011. Gene-environment interaction in psychological traits and disorders. Annu. Rev. Clin. Psychol. 7:383-409

Dick DM, Jones K, Saccone N, Hinrichs A, Wang JC, et al. 2006. Endophenotypes successfully lead to gene identification: results from the Collaborative Study on the Genetics of Alcoholism. Behav. Genet. $36: 112-26$

Duncan LE, Keller MC. 2011. A critical review of the first 10 years of candidate gene-by-environment interaction research in psychiatry. Am. F. Psychiatry 168:1041-49

Edgar JC, Hanlon FM, Huang MX, Weisend MP, Thoma RJ, et al. 2008. Superior temporal gyrus spectral abnormalities in schizophrenia. Psychophysiology 45:812-24

Eisenberg DP, Berman KF. 2010. Executive function, neural circuitry, and genetic mechanisms in schizophrenia. Neuropsychopharmacology 35:258-77

Esslinger C, Kirsch P, Haddad L, Mier D, Sauer C, et al. 2009. Cognitive state and connectivity effects of the genome-wide significant psychosis variant in ZNF804A. Neurolmage 54:2514-23

Euser AS, Arends LR, Evans BE, Greaves-Lord K, Huizink AC, Franken IH. 2012. The P300 event-related brain potential as a neurobiological endophenotype for substance use disorders: a meta-analytic investigation. Neurosci. Biobehav. Rev. 36:572-603

Flint J, Munafo MR. 2007. The endophenotype concept in psychiatric genetics. Psychol. Med. 37:163-80

Frances AJ, Widiger T. 2012. Psychiatric diagnoses: lessons learned from the DSM-IV past and cautions for the DSM-5 future. Annu. Rev. Clin. Psychol. 8:109-30

Friedman NP, Miyake A, Young SE, DeFries JC, Corley RP, Hewitt JK. 2008. Individual differences in executive functions are almost entirely genetic in origin. 7. Exp. Psychol.: Gen. 137:201-25

Giakoumaki SG, Roussos P, Pallis EG, Bitsos P. 2011. Sustained attention and working memory deficits follow a familial pattern in schizophrenia. Arch. Clin. Neuropsycbol. 26:687-95

Gilmore CS, Malone SM, Bernat EM, Iacono WD. 2010a. Relationship between the P3 event-related potential, its associated time-frequency components, and externalizing psychopathology. Psychophysiology 47:123-32

Gilmore CS, Malone SM, Iacono WD. 2010b. Brain electrophysiological endophenotypes for externalizing psychopathology: a multivariate approach. Behav. Genet. 40:186-200

Glahn DC, Almasy L, Barquil M, Hare E, Peralta JM, et al. 2010. Neurocognitive endophenotypes for bipolar disorder identified in multiplex multigenerational families. Arch. Gen. Psychiatry 67:168-77 
Glahn DC, Curran JE, Winkler AM, Carless MA, Kent CW, et al. 2012. High dimensional endophenotype ranking in the search for major depression risk genes. Biol. Psychiatry 71:6-14

Glahn DC, Therman S, Manninen M, Huttunen M, Kaprio J, et al. 2003. Spatial working memory as an endophenotype for schizophrenia. Biol. Psycbiatry 53:624-26

Golden RR, Meehl PE. 1979. Detection of the schizoid taxon with MMPI indicators. 7. Abnorm. Psychol. $88: 217-33$

Goldhaber D. 2012. The Nature-Nurture Debates: Bridging the Gap. New York: Cambridge Univ. Press

Goldman D. 2012. Our Genes, Our Choices: How Genotype and Gene Interactions Affect Bebavior. Waltham, MA: Academic

Gotlib IH, Hamilton JP. 2012. Bringing genetics back to psychiatric endophenotypes. Biol. Psychiatry 71:2-3

Gottesman II. 1963. Heritability of personality: a demonstration. Psychol. Monogr. 77:1-21

Gottesman II, Gould TD. 2003. The endophenotype concept in psychiatry: etymology and strategic intentions. Am. 7. Psychiatry 160:636-45

Gottesman II, Shields J. 1967. A polygenic theory of schizophrenia. Proc. Natl. Acad. Sci. USA 58:199-205

Gottesman II, Shields J. 1972. Schizophrenia and Genetics: A Twin Study Vantage Point. New York: Academic

Gottesman II, Shields J. 1973. Genetic theorizing and schizophrenia. Br. F. Psychiatry 122:15-30

Gould TD, Gottesman II. 2006. Psychiatric endophenotypes and the development of valid animal models. Genes Brain Behav. 5:113-19

Greenwood TA, Light GA, Swerdlow NR, Radant AD, Braff DL. 2012. Association analysis of 94 candidate genes and schizophrenia-related endophenotypes. PLoS ONE 7:e29630

Gregoire S, Rivalan M, Le Moine C, Dellu-Hagedorn F. 2012. The synergy of working memory and inhibitory control: behavioral, pharmacological and neural functional evidences. Neurobiol. Learn. Mem. 97:202-12

Grove WM. 1991. When is a diagnosis worth making? A statistical comparison of two prediction strategies. Psychol. Rep. 69:3-17

Gur RE, Calkins ME, Gur RC, Horan WP, Nuechterlein KH, et al. 2007a. The Consortium on the Genetics of Schizophrenia: neurocognitive endophenotypes. Schizophr. Bull. 33:49-68

Gur RE, Nimgaonkar VL, Almasy L, Calkins ME, Ragland JD, et al. 2007b. Neurocognitive endophenotypes in a multiplex multigenerational family study of schizophrenia. Am. 7. Psychiatry 164:813-19

Hasler G, Drevets WC, Gould TD, Gottesman II, Janji HK. 2006. Toward constructing an endophenotype strategy for bipolar disorders. Biol. Psychiatry 60:93-105

Hasler G, Drevets WC, Manji HK, Charney DS. 2004. Discovering endophenotypes for major depression. Neuropsychopharmacology 29:1765-81

Hasler G, Northoff G. 2011. Discovering imaging endophenotypes for major depression. Mol. Psychiatry 16:604-19

Heinrichs RW. 2004. Meta-analysis and the science of schizophrenia: variant evidence or evidence of variants? Neurosci. Biobehav. Rev. 28:379-94

Heston L. 1970. The genetics of schizophrenia and schizoid disease. Science 167:249-56

Hill SY. 2010. Neural plasticity, human genetics, and risk for alcohol dependence. Int. Rev. Neurobiol. 91:53-89

Hunsaker MR. 2012. Comprehensive neurocognitive endophenotyping strategies for mouse models of genetic disorders. Prog. Neurobiol. 96:220-41

Hyman SE. 1998. NIMH during the tenure of Director Steven E. Hyman, MD. (1996-present): the now and future of NIMH. Am. 7. Psychiatry 155:36-40

Hyman SE. 2010. The diagnosis of mental disorder: the problem of reification. Annu. Rev. Clin. Psychol. 6:155-79

Iacono WG. 1982. The genetics of psychopathology as a tool for understanding the brain: the search for a genetic marker of schizophrenia. In Genetics of the Brain, ed. I Lieblich, pp. 61-91. Amsterdam: Elsevier/North Holland

Iacono WG. 1983. Psychophysiology and genetics: a key to psychopathology research. Psychophysiology 20:37183

Iacono WG. 1985. Psychophysiological markers of psychopathology: a review. Can. Psychol. 26:96-112

Iacono WG. 1998. Identifying psychophysiological risk for psychopathology: examples from substance abuse and schizophrenia research. Psychophysiology 35:621-37 
Iacono WG, Carlson SR, Malone SM. 2000. Identifying a multivatriate endophenotype for substance use disorders using psychophysiological measures. Int. 7. Psychophysiol. 38:81-96

Iacono WG, Lykken DT. 1979. Eye tracking and psychopathology: new procedures applied to a sample of normal monozygotic twins. Arch. Gen. Psychiatry 36:1361-69

Iacono WG, Malone SM. 2011. Developmental endophenotypes: indexing genetic risk for substance abuse with the P300 brain event-related potential. Child Dev. Perspect. 5:239-47

Insel TR. 2012. Words matter. NIMH Director's Blog. http://www.nimh.nih.gov/about/director/2012/ words-matter.shtml

Insel TR, Cuthbert BN. 2009. Endophenotypes: bridging genomic complexity and disorder heterogeneity. Biol. Psychiatry 66:988-89

Insel TR, Cuthbert BN, Garvey M, Heinssen R, Pine DS, et al. 2010. Research Domain Criteria (RDoC): toward a new classification framework for research on mental disorders. Am. 7. Psychiatry 167:748-51

Int. Schizophr. Consort. 2009. Common polygenic variation contributes to risk of schizophrenia and bipolar disorder. Nature 460:748-52

Ivleva EI, Morris DW, Osuji J, Moates AF, Carmody TJ, et al. 2012. Cognitive endophenotypes of psychosis within dimension and diagnosis. Psychiatry Res. 196:38-44

Jaaro-Peled H, Hayashi-Takagi A, Seshadri S, Kamiya A, Brandon NJ, Sawa A. 2009. Neurodevelopmental mechanisms of schizophrenia: understanding disturbed postnatal brain maturation through neuregulin1-ErbB4 and DISC1. Trends Neurosci. 32:485-95

Jabben N, Arts B, van Os J, Krabbendam L. 2010. Neurocognitive functioning as intermediary phenotype and predictor of psychosocial functioning across the psychosis continuum: studies in schizophrenia and bipolar disorder. 7. Clin. Psychiatry 71:64-74

Jablensky A. 2010. The diagnostic concept of schizophrenia: its history, evolution, and future prospects. Dialogues Clin. Neurosci. 12:271-87

Jablensky A, Morar B, Wiltshire S, Carter K, Dragovic M, et al. 2011. Polymorphisms associated with normal memory variation also affect memory impairment in schizophrenia. Genes Brain Behav. 10:410-17

John B, Lewis K. 1966. Chromosome variability and geographic distribution in insects. Science 152:711-21

Johnson W, Turkheimer E, Gottesman II, Bouchard TJJr. 2009. Beyond heritability: twin studies in behavioral research. Curr. Dir. Psychol. Sci. 18:217-20

Juselius S, Kieseppä T, Kaprio J, Lönnqvist J, Tuulio-Henriksson A. 2009. Executive functioning in twins with bipolar I disorder and healthy co-twins. Arch. Clin. Neuropsychol. 24:599-606

Kaffman A, Krystal JJ. 2012. New frontiers in animal research of psychiatric illness. Methods Mol. Biol. 829:3-30

Kapur S, Phillips AG, Insel TR. 2012. Why has it taken so long for biological psychiatry to develop clinical tests and what to do about it? Mol. Psychiatry. 17:1174-79

Karlsgodt KH, Bachman P, Winkler AM, Bearden CE, Glahn DC. 2011. Genetic influence on the working memory circuitry: behavior, structure, function and extensions to illness. Bebav. Brain Res. 225:610-22

Karlsgodt KH, Kochuniv P, Winkler AM, Laird AR, Almasy L, et al. 2010. A multimodal assessment of the genetic control over working memory. F. Neurosci. 30:8197-202

Kazdin AE. 2007. Mediators and mechanisms of change in psychotherapy research. Annu. Rev. Clin. Psychol. $3: 1-27$

Kendler KS. 2005a. "A gene for...": The nature of gene action in psychiatric disorders. Am. F. Psychiatry $162: 1243-52$

Kendler KS. 2005b. Toward a philosophical structure for psychiatry. Am. F. Psychiatry 162:433-40

Kendler KS. 2011. A conceptual overview of gene-environment interaction and correlations in a developmental context. In The Dynamic Genome and Mental Health: The Role of Genes and Environments in Youth Development, ed. KS Kendler, SR Jaffee, D Romer, pp. 5-28. New York: Oxford Univ. Press

Kendler KS, Neale MC. 2010. Endophenotypes: a conceptual analysis. Mol. Psychiatry 15:789-97

Kety SS, Rosenthal D, Wender PH, Schulsiner F. 1968. The types and prevalence of mental illness in the biological and adoptive families of adopted schizophrenics. In The Transmission of Schizophrenia, ed. D Rosenthal, SS Kety, pp. 345-62. Oxford, UK: Pergamon

Kozak MJ, Miller GA. 1982. Hypothetical constructs versus intervening variables: a re-appraisal of the threesystems model of anxiety assessment. Behav. Assess. 14:347-58 
Krueger RF, Markon KE, Partick CJ, Iacono WG. 2005. Externalizing psychopathology in adulthood: a dimensional-spectrum conceptualization and its implications for DSM-V. F. Almorm. Psychol. 114:537-50

Laland KN, Odling-Smee J, Myles S. 2010. How culture shaped the human genome: bringing genetics and the human sciences together. Nat. Rev. Genet. 11:137-48

Lederbogen F, Kirsch P, Haddad L, Streit F, Trost H, et al. 2011. City living and urban upbringing affect neural social stress processing in humans. Nature 474:498-501

Lennertz L, Quednow BB, Benninghoff J, Wagner M, Maier W, Mössner R. 2011a. Impact of TCF4 on the genetics of schizophrenia. Eur. Arcb. Psycbiatr. Clin. Neurosci. 261(Suppl. 2):S161-65

Lennertz L, Rujescu D, Wagner M, Frommann I, Schulze-Rauschenbach S, et al. 2011b. Novel schizophrenia risk gene TCF4 influences verbal learning and memory functioning in schizophrenia patients. Neuropsychobiology 63:131-6

Lenzenweger MF. 2010. Schizotypy and Schizophrenia: The View from Experimental Psychopathology. New York: Guilford

Levin RL, Heller W, Mohanty A, Herrington JD, Miller GA. 2007. Cognitive deficits in depression and functional specificity of regional brain activity. Cogn. Ther. Res. 31:211-33

Lilienfeld SO. 2007. Cognitive neuroscience and depression: legitimate versus illegitimate reductionism and five challenges. Cogn. Ther. Res. 31:263-72

Lu BY, Martin KE, Edgar JC, Smith AK, Lewis SF, et al. 2007. Effect of catechol-O-methyltransferase val(158)met polymorphism on the P50 gating endophenotype in schizophrenia. Biol. Psycbiatry 62:822 25

Lubke GH, Hottenga JJ, Walters R, Laurin C, de Geus EJC, et al. 2012. Estimating the genetic variance of major depressive disorder due to all single nucleotide polymorphisms. Biol. Psychiatry 72:707-9

Lutkenhoff E, Karlsgodt KH, Gutman B, Stein JL, Thompson PJ, et al. 2012. Structural and functional neuroimaging phenotypes in dysbindin mutant rice. Neurolmage 62:120-29

Lykken DT, McGue M, Tellegen A, Bouchard TJ Jr. 1992. Emergenesis: genetic traits that may not run in families. Am. Psychol. 47:1565-77

MacDonald AW III, Thermenos HW, Barch DM, Seidman LJ. 2009. Imaging genetic liability to schizophrenia: systematic review of fMRI studies of patients' nonpsychotic relatives. Schizophr. Bull. 35:1142-62

MacLeod C, Mathews A. 2012. Cognitive bias modification approaches to anxiety. Annu. Rev. Clin. Psychol. 8:189-217

Mann JJ, Arango VA, Avenevoli S, Brent DA, Champagne FA, et al. 2009. Candidate endophenotypes for genetic studies of suicidal behavior. Biol. Psychiatry 65:556-63

Manoach DS. 2003. Prefrontal cortex dysfunction during working memory performance in schizophrenia: reconciling discrepant findings. Schizophr. Res. 60:285-98

Markett S, Montag C, Walter NT, Plieger T, Reuter M. 2011. On the molecular genetics of flexibility: the case of task-switching inhibitory control and genetic variants. Cogn. Affect. Behav. Neurosci. 11:644-51

Markon KE, Chmielewski M, Miller CJ. 2011. The reliability and validity of discrete and continuous measures of psychopathology: a quantitative review. Psychol. Bull. 137:856-79

Mazhari S, Price G, Dragović M, Waters FA, Clissa P, Jablensky A. 2011. Revisiting the suitability of antisaccade performance as an endophenotype in schizophrenia. Brain Cogn. 77:223-30

Meaney MJ. 2001. Maternal care, gene expression, and the transmission of individual differences in stress reactivity across the generations. Annu. Rev. Neurosci. 24:1161-92

Meda SA, Gill A, Stevens MC, Lorenzoni RP, Glahn DC, et al. 2012a. Differences in resting-state functional magnetic resonance imaging functional network connectivity between schizophrenia and psychotic bipolar probands and their unaffected first-degree relatives. Biol. Psychiatry 71:881-89

Meda SA, Jagannathan K, Gelernter J, Calhoun VD, Liu J, et al. 2010. A pilot multivariate parallel ICA study to investigate differential linkage between neural networks and genetic profiles in schizophrenia. NeuroImage 53:1007-15

Meda SA, Narayanan B, Liu J, Perrone-Bizzozero NI, Stevens MC, et al. 2012b. A large scale multivariate parallel ICA method reveals novel imaging-genetic relationships for Alzheimer's disease in the ADNI cohort. NeuroImage 60:1608-21

Meehl PE. 1962. Schizotaxia, schizotypy, schizophrenia. Am. Psycbol. 17:827-38 
Meehl PE. 1972. A critical afterword. In Schizophrenia and Genetics: A Twin Study Vantage Point, ed. II Gottesman, J Shields, pp. 367-415. New York: Academic

Meehl PE. 1977. Specific etiology and other forms of strong influence: some quantitative meanings. 7. Med. Philos. 2:33-53

Meehl PE. 1978. Theoretical risks and tabular asterisks: Sir Karl, Sir Ronald and the slow progress of soft psychology. 7. Consult. Clin. Psychol. 46:806-34

Meyer-Lindenberg A. 2010. From maps to mechanisms through neuroimaging of schizophrenia. Nature 468:194-202

Miller GA. 1996. How we think about cognition, emotion, and biology in psychopathology. Psychopbysiology 21:257-64

Miller GA. 2004. Another quasi-thirty years of slow progress. Appl. Prev. Psychol. 11:61-64

Miller GA. 2010. Mistreating psychology in the decades of the brain. Perspect. Psychol. Sci. 5:716-43

Miller GA, Chapman JP. 2001. Misunderstanding analysis of covariance. F. Alnorm. Psychol. 110:40-48

Miller GA, Elbert T, Sutton BP, Heller W. 2007. Innovative clinical assessment technologies: challenges and opportunities in neuroimaging. Psychol. Assess. 19:58-73

Miller GA, Keller J. 2000. Psychology and neuroscience: making peace. Curr. Dir. Psychol. Sci. 9:212-5

Miller MB, Chapman JP, Chapman LJ, Collins J. 1995. Task difficulty and cognitive deficits in schizophrenia. 7. Abnorm. Psychol. 104:251-58

Morris SE, Cuthbert BN. 2012. Research Domain Criteria: cognitive systems, neural circuits, and dimensions of behavior. Dialogues Clin. Neurosci. 14:29-37

Moskvina V, Craddock N, Holmans P, Nikolov I, Pahwa JS, et al. 2009. Gene-wide analyses of genome-wide association data sets: evidence for multiple common risk alleles for schizophrenia and bipolar disorder and for overlap in genetic risk. Mol. Psycbiatry 14:252-60

Munakata Y, Herd SA, Chatham CH, Depue BE, Banich MT, O'Reilly C. 2011. A unified framework for inhibitory control. Trends Cogn. Sci. 15:453-59

Neelam K, Garg D, Marshall M. 2011. A systematic review and meta-analysis of neurological soft signs in relatives of people with schizophrenia. BMC Psychiatry 11:139

Niendam TA, Laird AR, Ray KL, Dean YM, Glahn DC, Carter CS. 2012. Meta-analytic evidence for a superordinate cognitive control network subserving diverse executive functions. Cogn. Affect. Bebav. Neurosci. 12:241-68

Noë A. 2009. Out of Our Heads: Why You Are Not Your Brain, and Other Lessons from the Biology of Consciousness. New York: Hill \& Wang

O'Driscoll GA, Florencio PS, Gagnon D, WolffALV, Benkelfat C, et al. 2001. Amygdala-hippocampal volume and verbal memory in first-degree relatives of schizophrenia patients. Psychiatry Res. 107:75-85

Oliver PL. 2011. Challenges of analysing gene-environment interactions in mouse models of schizophrenia. ScientificWorldfournal 11:1411-20

Owen MJ. 2012. Implications of genetic findings for understanding schizophrenia. Scbizopbr. Bull. 38:904-7

Owens SF, Rijsdijk F, Picchioni MM, Stahl D, Nenadic I, et al. 2011. Genetic overlap between schizophrenia and selective components of executive function. Schizophr. Res. 127:181-87

Pantelis C, Wood SJ, Velakoulis D, Testa R, Fontenelle LF, Yücel M. 2010. Should we redefine the concept of endophenotypes in schizophrenia? Rev. Bras. Psiquiatr. 32:106-7

Papassotiropoulos A, de Quervain DJ. 2011. Genetics of human episodic memory: dealing with complexity. Trends Cogn. Sci. 15:381-87

Paris J. 2011. Endophenotypes and the diagnosis of personality disorders. F. Personal. Disord. 25:260-68

Patrick CJ, Venables NC, Yancey JR, Hicks BM, Nelson LD, Kramer MD. 2012. A construct-network approach to bridging diagnostic and physiological domains: application to assessment of externalizing psychopathology. 7. Abnorm. Psychol. In press

Pearlson GD, Calhoun VD. 2009. Convergent approaches for defining functional imaging endophenotypes in schizophrenia. Front. Hum. Neurosci. 3:1-11

Pearlson GD, Folley BS. 2008. Endophenotypes, dimensions, risks: Is psychosis analogous to common inherited medical illnesses? Clin. EEG Neurosci. 39:73-77 
Petrovsky N, Quednow BB, Ettinger U, Schmechting A, Rössner R, et al. 2010. Sensorimotor gating is associated with CHRNA3 polymorphisms in schizophrenia and healthy volunteers. Neuropsychopharmacology $25: 1429-39$

Popov T, Jordanov T, Rockstroh B, Elbert T, Merzenich MM, Miller GA. 2011. Specific cognitive training normalizes auditory sensory gating in schizophrenia: a randomized trial. Biol. Psychiatry 69:465-71

Powell SB, Zhou X, Geyer MA. 2009. Prepulse inhibition and genetic mouse models of schizophrenia. Bebav. Brain Res. 204:282-94

Preston GA, Weinberger DR. 2005. Intermediate phenotypes in schizophrenia: a selective review. Dialogues Clin. Neurosci. 7:165-79

Quednow BB, Schmechting A, Ettinger U, Petrovsky N, Collier DA, et al. 2009. Sensorimotor gating depends on polymorphisms of the serotonin-2A receptor and catechol-O-methyltransferase, but not neuregulin-1 Arg38Gln genotype: a replication study. Biol. Psychiatry 66:614-20

Radtke KM, Ruf M, Gunter HH, Dohrmann K, Schauer M, et al. 2011. Transgenerational impact of intimate partner violence on methylation in the promoter of the glucocorticoid receptor. Transl. Psycbiatry 1:e21

Rao NP, Kumar KJ, Kandavel T, Chandrashekar CR. 2008. Are neuropsychological deficits trait markers in OCD? Progr. Neuropharmacol. Biol. Psychiatry 32:1574-79

Reichborn-Kjennerud T. 2010. The genetic epidemiology of personality disorders. Dialogues Clin. Neurosci. 12:103-14

Ritsner MS. 2011. Toward a multidimensional continuum model of functional psychoses for research purposes. In Handbook of Schizophrenia Spectrum Disorders, ed. MS Ritsner, pp. 85-114. Amsterdam: Springer

Ritsner MS, Gottesman II. 2009. Where do we stand in the quest for neuropsychiatric biomarkers and endophenotypes and what next? In The Handbook of Neuropsychiatric Biomarkers, Endophenotypes and Genes, ed. MS Ritsner, pp. 3-21. Amsterdam: Springer

Ritsner MS, Gottesman II. 2011. The schizophrenia construct after 100 years of challenges. In Handbook of Schizophrenia Spectrum Disorders, Vol. I, ed. MS Ritsner, pp. 1-44. New York: Springer

Robbins TW, Gillan CM, Smith DG, de Wit S, Ersche KD. 2012. Neurocognitive endophenotypes of impulsivity and compulsivity: towards dimensional psychiatry. Trends Cogn. Sci. 16:81-91

Roberts BW, Kuncel NR, Shiner R, Caspi A, Goldberg LR. 2007. The power of personality: the comparative validity of personality traits, socioeconomic status, and cognitive ability for predicting important life outcomes. Perspect. Psychol. Sci. 2:313-45

Rosburg T, Boutros NN, Ford JM. 2008. Reduced auditory evoked potential component N100 in schizophrenia-a critical review. Psychiatry Res. 161:259-74

Rutten BP, Mill J. 2009. Epigenetic mediation of environmental influences in major psychotic disorders. Schizophr. Bull. 35:1045-56

Sabb FW, Burggren AC, Higier RG, Fox J, He J, et al. 2009. Challenges in phenotype definition in the whole-genome era: multivariate models of memory and intelligence. Neuroscience 164:88-107

Sanislow CA, Pine DS, Quinn KJ, Kozak MJ, Garvey MA, et al. 2010. Developing constructs for psychopathology research: Research Domain Criteria. F. Abnorm. Psychol. 119:631-39

Sass SM, Heller W, Stewart JL, Silton RL, Edgar C, et al. 2010. Time course of attentional bias to threat in anxiety: emotion and gender specificity. Psychophysiology 47:247-59

Savitz JB, Solms M, Ramesar RS. 2005. Neurocognitive function as an endophenotype for genetic studies of bipolar affective disorder. Neuromolecular Med. 7:275-86

Savitz JB, van der Merwe L, Stein DJ, Solms M, Ramesar RS. 2008. Neuropsychological task performance in bipolar spectrum illness: genetics, alcohol abuse, medication and childhood trauma. Bipolar Disord. 10:479-94

Schulze KK, Walshe M, Stahl D, Hall MH, Kravarti E, et al. 2011. Executive functioning in familial bipolar I disorder patients and their unaffected relatives. Bipolar Disord. 13:208-16

Shaikh M, Hall MH, Schulze K, Dutt A, Walshe M, et al. 2011. Do COMT, BDNF and NRG1 polymorphisms influence P50 sensory gating in psychosis? Psychol. Med. 41:263-76

Siever J. 2005. Endophenotypes in the personality disorders. Dialogues Clin. Neurosci. 7:139-51

Singh SM, Basu D. 2009. The P300 event-related potential and its possible role as an endophenotype for studying substance abuse disorders: a review. Addict. Biol. 14:298-309 
Skodol AE. 2012. Personality disorders in DSM-5. Annu. Rev. Clin. Psychol. 8:317-44

Smith AK, Edgar JC, Huang M, Lu BY, Thoma RJ, et al. 2010. Cognitive abilities and 50- and 100-msec paired-click processes in schizophrenia. Am. 7. Psychiatry 167:1264-75

Stone WS, Giuliano AJ, Tsuang MT, Braff DL, Cadenhead KS, et al. 2011. Group and site differences on the California Verbal Learning Test in persons with schizophrenia and their first-degree relatives: findings from the Consortium on the Genetics of Schizophrenia (COGS). Schizophr. Res. 128:102-10

Sullivan PF, Daly MJ, O'Donovan M. 2012. Genetic architectures of psychiatric disorders: the emerging picture and its implications. Nat. Rev. Genet. 13:537-51

Swerdlow NR, Weber M, Qu Y, Light GA, Braff DL. 2008. Realistic expectations of prepulse inhibition in translational models for schizophrenia research. Psychopharmacology 199:331-88

Takahashi N, Nielsen KS, Aleksic B, Petersen S, Ikeda M, et al. 2011. Loss of function studies in mice and genetic association link receptor protein tyrosine phosphatase $\alpha$ to schizophrenia. Biol. Psychiatry 70:626-35

Tan H-Y, Callicott JH, Weinberger DR. 2008. Intermediate phenotypes in schizophrenia genetics redux: Is it a no brainer? Mol. Psycbiatry 13:233-38

Tarbox SI, Pogue-Geile MF. 2011. A multivariate perspective on schizotypy and familial association with schizophrenia: a review. Clin. Psychol. Rev. 31:1169-82

Thaker G. 2008a. Neurophysiological endophenotypes across bipolar and schizophrenia psychosis. Schizophr. Bull. 34:760-73

Thaker G. 2008b. Psychosis endophenotypes in schizophrenia and bipolar disorder. Schizophr. Bull. 34:720-21

Thapar A, Harold G, Rice F, Langley K, O'Donovan M. 2007. The contribution of gene-environment interaction to psychopathology. Dev. Psychopathol. 19:989-1004

Turetsky BI, Calkins ME, Light GA, Olincy A, Radant AD, Swerlow NR. 2007. Neurophysiological endophenotypes of schizophrenia: the viability of selected candidate measures. Schizophr. Bull. 33:69-94

Turetsky BI, Greenwood TA, Olincy A, Radant AD, Braff DL, et al. 2008. Abnormal auditory N100 amplitude: a heritable endophenotype in first-degree relatives of schizophrenia probands. Biol. Psychiatry 164:105159

Turkheimer E. 2000. Three laws of behavior genetics and what they mean. Curr. Dir. Psychol. Sci. 9:160-64

Turkheimer E, Goldsmith HH, Gottesman II. 1995. Commentary. Hum. Dev. 38:142-53

Turkheimer E, Haley A, Waldron M, D'Onofrio B, Gottesman II. 2003. Socioeconomic status modifies heritability of IQ in young children. Psychol. Sci. 14:623-28

Tuulio-Henriksson A, Arajärvi R, Partonen T, Haukka J, Varilo T, et al. 2003. Familial loading associates with impairment in visual span among healthy siblings of schizophrenia patients. Biol. Psychiatry 54:623-28

Uhl GR, Dragon T, Johnson C, Li CY, Contoreggi C, et al. 2008. Molecular genetics of addiction and related heritable phenotypes: genome-wide association approaches identify "connectivity constellation" and drug target genes with pleiotropic effects. Ann. N. Y. Acad. Sci. 1141:318-81

Uttal WR. 2011. Mind and Brain: A Critical Appraisal of Cognitive Neuroscience. Cambridge, MA: MIT Press

Van Os J, Kenis G, Rutten BP. 2010. The environment and schizophrenia. Nature 468:203-12

Venables NC, Bernat EM, Sponheim S. 2009. Genetic and disorder-specific aspects of resting state EEG abnormalities in schizophrenia. Scbizophr. Bull. 35:826-39

Vrieze SI. 2012. Model selection and psychological theory: a discussion of the differences between the Akaike Information Criterion (AIC) and the Bayesian Information Criterion (BIC). Psychol. Methods 17:228-43

Vrieze SI, Iacono WG, McGue M. 2012a. Confluence of genes, environment, development, and behavior in a post-GWAS world. Dev. Psychopathol. 24:1195-214

Vrieze SI, Perlman G, Krieger RF, Iacono WG. 2012b. Is the continuity of externalizing psychopathology the same in adolescents and middle-aged adults? A test of the externalizing spectrum's developmental coherence. 7. Abnorm. Cbild Psychol. 40:459-70

Walshaw PD, Alloy LB, Sabb FW. 2010. Executive function in pediatric bipolar disorder and attention-deficit hyperactivity disorder: in search of distinct phenotypic profiles. Neuropsychol. Rev. 20:103-20

Walters JT, Owen MJ. 2007. Endophenotypes in psychiatric genetics. Mol. Psychiatry 12:886-90

White T, Gottesman I. 2012. Brain connectivity and gyrification as endophenotypes for schizophrenia: weight of the evidence. Curr. Topics Med. Chem. In press 
Widiger TA. 2011. The DSM-5 dimensional model of personality disorders: rationale and empirical support. 7. Personal. Disord. 25:222-34

Widiger TA, Mullins-Sweat SN. 2009. Five-factor model of personality disorder: a proposal for DSM-V. Annu. Rev. Clin. Psychol. 5:115-38

Williams TJ, Nuechterlein KH, Subotnik KL, Yee CM. 2011. Distinct neural generators of sensory gating in schizophrenia. Psychophysics 48:470-78

Wobrock T, Ecker UK, Scherk H, Schneider-Axmann T, Falkai P, Gruber O. 2009. Cognitive impairment of executive function as a core symptom in schizophrenia. World 7. Biol. Psychiatry 10:442-51

World Health Organ. 2010. International Classification of Diseases. Geneva: World Health Organ. 10th rev.

Zinbarg RE, Suzuki S, Uliaszek AA, Lewis AR. 2010. Biased parameter estimates and inflated type I error rates in analysis of covariance (and analysis of partial variance) arising from unreliability: alternatives and remedial strategies. 7. Abnorm. Psychol. 119:307-19 